\title{
Construction of Synthetic Models for Nitrogenase-Relevant NifB Biogenesis Intermediates and Iron-Carbide-Sulfide Clusters
}

\author{
Chris Joseph ${ }^{\circledR}$, John Patrick Shupp $®$, Caitlyn R. Cobb $®$ and Michael J. Rose *® \\ Department of Chemistry, The University of Texas at Austin, Austin, TX 78712, USA; \\ cjoseph14@utexas.edu (C.J.); jpshupp@utexas.edu (J.P.S.); caitlyn_cobb@utexas.edu (C.R.C.) \\ * Correspondence: mrose@cm.utexas.edu
}

Received: 14 October 2020; Accepted: 10 November 2020; Published: 13 November 2020

\begin{abstract}
The family of nitrogenase enzymes catalyzes the reduction of atmospheric dinitrogen $\left(\mathrm{N}_{2}\right)$ to ammonia under remarkably benign conditions of temperature, pressure, and $\mathrm{pH}$. Therefore, the development of synthetic complexes or materials that can similarly perform this reaction is of critical interest. The primary obstacle for obtaining realistic synthetic models of the active site iron-sulfur-carbide cluster (e.g., FeMoco) is the incorporation of a truly inorganic carbide. This review summarizes the present state of knowledge regarding biological and chemical (synthetic) incorporation of carbide into iron-sulfur clusters. This includes the Nif cluster of proteins and associated biochemistry involved in the endogenous biogenesis of FeMoco. We focus on the chemical (synthetic) incorporation portion of our own efforts to incorporate and modify $C_{1}$ units in iron/sulfur clusters. We also highlight recent contributions from other research groups in the area toward $C_{1}$ and/or inorganic carbide insertion.
\end{abstract}

Keywords: nitrogenase; biomimetic; FeMoco; NifB-co; carbide; biogenesis

\section{Introduction}

\subsection{Structural Determination of the Resting Nitrogenase Active Site}

The nitrogenases are a class of enzymes that catalyze ammonia synthesis from dinitrogen and are the only biological systems known to catalyze the $\mathrm{N}_{2} \rightarrow 2 \mathrm{NH}_{3}$ conversion. In contrast to the $\mathrm{H}_{2}$-consuming Haber-Bosch process, dinitrogen fixation by nitrogenase $\left(\mathrm{N}_{2}\right.$ ase $)$ is achieved via coupled proton/electron transfer directed toward the substrate [1]. Three variants of nitrogenase are known: Mo-dependent, V-dependent, and Fe-type. The Mo-dependent nitrogenase, however, exhibits the highest rate of catalytic activity and has been the focus of the majority of biocatalytic dinitrogen-reduction research [2]. The crystal structure of the molybdenum-containing nitrogenase was first reported in 1992 by Rees et al. to $2.9 \AA$ resolution (Figure 1). This structure revealed a homodimeric enzyme in which each monomer consists of two components: (1) nitrogenase (MoFe protein in Mo-dependent nitrogenase) in which the catalytic active site is contained, and (2) nitrogenase reductase (Fe protein), which is an electron-transfer protein [3,4]. The active site contained in the MoFe protein was initially described as a two-component active site comprised of two clusters: a $4 \mathrm{Fe}: 3 \mathrm{~S}$ cluster and a 1Mo:3Fe:3S cluster bridged by three non-protein ligands (designated as two sulfides and one unresolved site). This iron-molybdenum cofactor (FeMoco) is tethered to the protein by two ligands coordinated to the two distal metal sites: a cysteine residue $\left(\mathrm{Cys}^{\alpha 275}\right)$ located at the distal iron site and a histidine residue (His ${ }^{\alpha 442}$ ) ligated to molybdenum. The molybdenum site is also coordinated by two oxygens from a bidentate homocitrate (HC) ligand. However, the six proximal Fe sites in this proposed structure appear to be supported by a non-planar, trigonal coordination sphere uncharacteristic for biological iron in a resting state enzyme. 
A decade following the 1992 report, a higher resolution structure (1.16 ̊ resolution) of FeMoco by Einsle, Rees et al., revealed the presence of a central, interstitial hexacoordinate light $(2 p)$ atom residing in the tetrahedral hole of the six proximal Fe sites $[5,6]$. Einsle and Rees initially postulated the site to be a nitride based on electron density integration studies. However, they suggested that carbon and oxygen could not be unambiguously discounted.
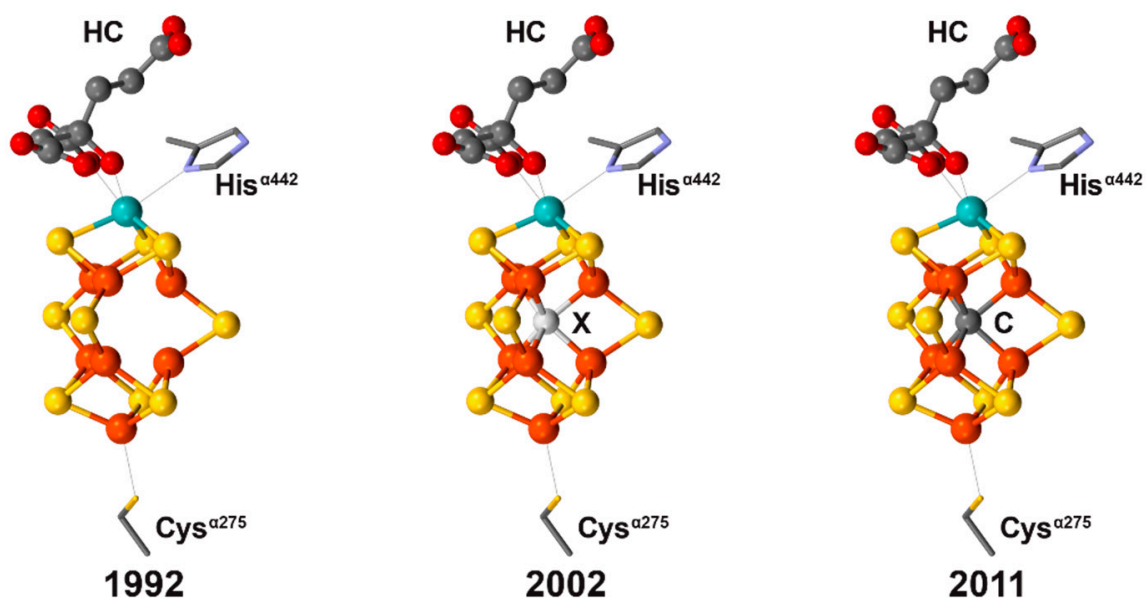

Figure 1. Progression of structure refinement for the iron-molybdenum cofactor (FeMoco) from structural X-ray diffraction (XRD) data and specialized Electron Paramagnetic Resonance (EPR) and X-ray emission (XES) data [3-8].

In 2011, two independent research efforts concurrently ascertained the identity of the central atom to be a carbide rather than a nitride (Figure 1). Rees, Einsle et al. confirmed the carbide experimentally by utilizing two separate experiments: (1) improved structural resolution (1.0 A) for electron density integration analysis and (2) comparative pulsed EPR-ESEEM (Electron Paramagnetic Resonance, Electron Spin Echo Envelope Modulation) on isotopically labeled $\left({ }^{13} \mathrm{C}\right.$ or $\left.{ }^{15} \mathrm{~N}\right) \mathrm{MoFe}$ protein (resting state $S=3 / 2)$ in which significant hyperfine coupling was observed in the ${ }^{13} \mathrm{C}$-labeled $(I=1 / 2)$ protein [7]. These monumental findings were printed onto a single page in the mid-November 2011 issue of Science. In the same issue, a publication of equal importance by DeBeer et al. utilized a combination of valence-to-core X-ray emission spectroscopy (V2C-XES) and computationally calculated spectra for cofactors bearing various interstitial atoms $\left(\mathrm{C}^{4-}, \mathrm{N}^{3-}\right.$, and $\left.\mathrm{O}^{2-}\right)$ to determine the identity of the interstitial atom [8]. The capability of V2C-XES to distinguish between light atoms within a multi-metallic cluster was demonstrated in a preceding study by DeBeer, Holland et al. comparing synthetic and computational model compounds bearing various interstitial atoms to differentiate between $\mathrm{Fe}_{6}$ hexacoordinate $\mathrm{C}, \mathrm{N}$, and $\mathrm{O}$ sites [9]. The results of these studies identified the interstitial atom in FeMoco as a purely inorganic carbide. Thus, the concurrent findings by the Einsle and DeBeer research groups unambiguously established the presence of an interstitial carbide in the $\mathrm{N}_{2}$ ase cofactor.

\subsection{Biological Synthesis of the FeMoco Cluster}

The biogenesis of nitrogenase is accomplished by a set of enzymes coded in the "nitrogen-fixing" (Nif) genes. NifS and NifU provide the initial conversion of cysteinyl thiolates and iron incorporation to produce the two inorganic $\mathrm{Fe}_{4} \mathrm{~S}_{4}$ iron-sulfur clusters to be transferred onto NifB for carbide insertion. The presence of a CXXXCXXC signature motif consistent with the presence of $S$-adenosylmethionine (SAM) led Ribbe and Hu to postulate the utilization of a SAM-dependent mechanism by NifB [10,11]. Using isotope-labeling experiments in conjunction with CW (Continuous-Wave) and pulse EPR, the origin of the carbide was determined to be a methyl group from SAM during cofactor assembly by NifB [11-13]. Following initial transfer from SAM onto a sulfide in the $\left(\mathrm{Fe}_{4} \mathrm{~S}_{4}\right)_{2} \mathrm{~K}$-cluster (Figure 2), the $\mathrm{CH}_{3}$ group undergoes $\mathrm{H}$-atom abstraction by an additional equivalent of $\mathrm{SAM}$, which is followed by continued, iterative deprotonation/dehydrogenation to form the L-cluster. The utility of SAM as 
a methyl transfer agent toward $s p^{2}$ and $s p^{3} \mathrm{C}$ sites has been previously reported, such as upon the tryptophanyl bicyclic ring [14] or in thienamycin biosynthesis [15]. Subsequent maturation by the NifEN assembly protein leads to substitution of a distal Fe site with $\mathrm{Mo}(\mathrm{HC})$ before final delivery into NifDK to achieve the final M-cluster [16-18].
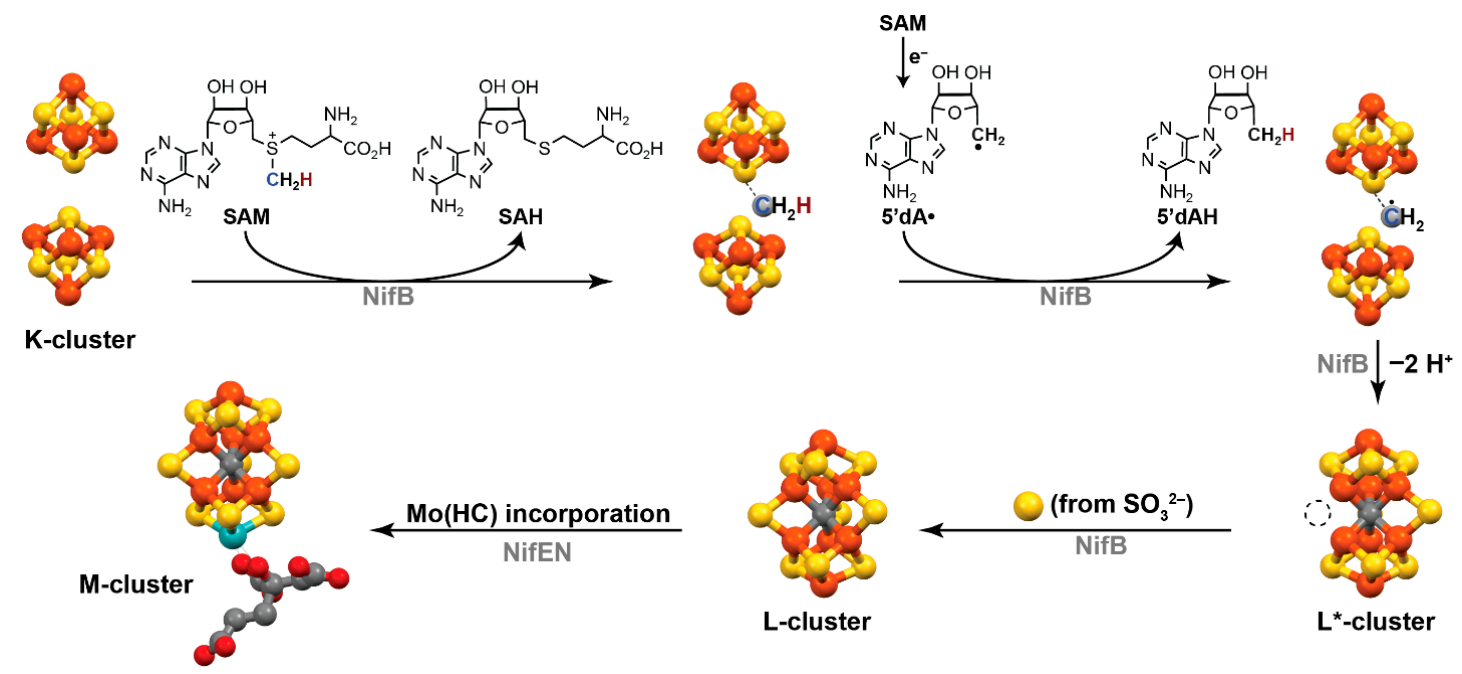

Figure 2. Proposed biosynthetic mechanism for carbide formation, insertion of the '9th' sulfide, and heterometal substitution prior to maturation of the MoFe protein as proposed by Ribbe and $\mathrm{Hu}$ [11-13,16-18]. Image adapted with permission from Joseph, C., Cobb, C. R., Rose, M. J. Single-Step Insertion of Sulfides and Thiolate into Iron Carbide-Carbonyl Clusters: Unlocking the Synthetic Door to FeMoco Analogues. Angew. Chemie Int. Ed. 2020. Accepted, not yet published. Copyright Wiley-VCH GmbH. Reproduced with permission.

Initial studies with nitrogenase utilized dithionite as the reductant, convoluting the origin of the "9th" sulfide into the cluster. As such, Ribbe et al. surveyed a suite of biologically relevant sulfur-containing sources-sulfides $\left(\mathrm{S}^{2-}\right)$, sulfites $\left(\mathrm{SO}_{3}{ }^{2-}\right)$, sulfates $\left(\mathrm{SO}_{4}{ }^{2-}\right)$ - and substituted Eu ${ }^{\mathrm{II}}$-EGTA as a reductant in their biogenesis studies to establish the role of an external sulfur source for M-cluster maturation [18]. It was demonstrated that only $\mathrm{SO}_{3}{ }^{2-}$ led to the formation of the L cluster. Additionally, when radiolabeled ${ }^{35} \mathrm{SO}_{3}{ }^{2-}$ was utilized, the radiolabel could be detected downstream in the extracted L-cluster. In biosynthetic experiments performed in the absence of SAM, no significant retention of the radiolabel was detected, suggesting that sulfide transfer likely occurs after incubation with SAM. Finally, incubation conditions in which SAM is present while $\mathrm{SO}_{3}{ }^{2-}$ is absent leads to the formation of an undefined $\mathrm{L}^{*}$-cluster (tentatively assigned as an $\mathrm{Fe}_{8} \mathrm{~S}_{8} \mathrm{C}$ cluster).

\subsection{Multimetallic Co-Operativity toward Dinitrogen Activation}

Initial insight into the nitrogenase mechanism was primarily founded upon extensive kinetic studies conducted throughout the 1970s to 1980s. Lowe and Thorneley famously proposed a rudimentary kinetic scheme whereby the resting-state $\mathrm{N}_{2}$ ase cofactor (designated $\mathrm{E}_{0}$ ) undergoes four iterative protonation/reduction events $\left(E_{1}-E_{4}\right)$, at which point, the stage is set for substrate binding. Concurrent with the liberation of one equiv $\mathrm{H}_{2}, \mathrm{~N}_{2}$ binds and proceeds to be reduced to two $\mathrm{NH}_{3}$ as the cofactor continues to undergo subsequent protonation and reduction. Liberation of the second equivalent $\mathrm{NH}_{3}$ returns the cofactor to its resting state, $\mathrm{E}_{0}$ [1]. The precise geometric and electronic structural details of the $\mathrm{E}_{1}-\mathrm{E}_{4}$ intermediates are still mostly unknown. However, recent spectroscopic and computational information about the $E_{1}$ state has begun to emerge, suggesting that the $E_{1}$ step involves reduction of an Fe site in conjunction with protonation of a belt-sulfide [19,20].

The location and mode of substrate-binding was a topic of considerable debate throughout the last two decades. The differences in $\mathrm{N}_{2}$-reducing activity between the $\mathrm{M}$-cluster, $\mathrm{V}$-cluster, and L-cluster 
nominated the heterometal (i.e., Mo in FeMoco) as a likely site for substrate binding. This conclusion gained additional support with the publication in 2003 of Schrock's synthetic, Mo-centered complex as the first report of a synthetic and functional $\mathrm{N}_{2}$-reducing catalyst with an $\mathrm{N}_{2}$ ase-relevant metal center [21]. In 2013, however, Peters published a synthetic Fe complex bearing a $2 p$ donor atom (B) in its ligation sphere and capable of catalytic $\mathrm{N}_{2}$ conversion [22]. Experimental and computational evidence with FeMoco and FeVco began to implicate iron as the likely $\mathrm{N}_{2}$-binding site. Inhibition of FeMoco with carbon monoxide (CO) and crystallization of the resulting MoFe protein revealed a structure in which the S2B belt sulfide-which bridges $\mathrm{Fe} 2$ and Fe6-is substituted with a bridging $\mathrm{CO}$ [23]. Additionally, treatment of FeMoco with KSeCN demonstrated similar lability of the belt sulfides: 1 equiv KSeCN under argon atmosphere resulted in substitution of S2B with Se [24]. Subsequent catalytic turnover with $\mathrm{N}_{2}$ produced structures in which the Se migrated to the $5 \mathrm{~A}$ or $3 \mathrm{~A}$ positions. Crystallization and $X$-ray diffraction (XRD) of vanadium-dependent $\mathrm{N}_{2}$ ase during turnover presented a FeVco structure in which the S2B position was occupied by a small bridging ligand (presumably $\mathrm{N}$ or $\mathrm{NH}_{\mathrm{x}}$, even though $\mathrm{O}$ or $\mathrm{OH}_{\mathrm{x}}$ cannot be discounted) [25]. Finally, the computational work surrounding the Mo site suggests that one of the oxygen donors dissociates from Mo during the $\mathrm{E}_{2}-\mathrm{E}_{4}$ steps, leaving a possible open coordination site. However, energy calculations suggest that activation of $\mathrm{N}_{2}$ at this site results in a significantly higher increase in energy and that $\mathrm{N}_{2}$ binding at $\mathrm{Fe}_{2}$ and $\mathrm{Fe}_{6}$ is much more thermodynamically favorable (though still endothermic) [26].

Furthermore, in early 2020, a ground-breaking crystallographic structure by Ribbe and Hu under physiological turnover conditions depicted a substrate-bound nitrogenase intermediate, which revealed details regarding the putative substrate binding sites as well as binding modes during turnover [27]. While the exact identities of the substrates remain unconfirmed $\left(\mathrm{N}_{2}\right.$ vs. $\mathrm{N}_{2} \mathrm{H}_{2}$ vs. $\left.\mathrm{N}_{2} \mathrm{H}_{4}\right)$, the structural data demonstrates displacement of the belt sulfides to allow for substrate binding at the medial Fe sites. The two FeMoco clusters in the structure exhibit distinct substrate-binding modes, such that the substrate presents in a 'side-on' binding mode in the chain A cluster or an 'end-on' mode in the chain $C$ cluster. In either case, the dinitrogen substrate adopts a bridged binding mode between two Fe sites, highlighting the significant role of multi-iron co-operativity toward the mechanism of dinitrogen activation and reduction by nitrogenase.

\subsection{Synthetic Model Compounds in FeMoco Biomimetics}

Throughout the past two decades of nitrogenase research, studies utilizing synthetic model compounds have contributed greatly to the early mechanistic and electronic discussions surrounding nitrogenase in lieu of highly sophisticated spectroscopic and computational techniques, which have only recently become available for studying the complicated active site. The Schrock catalyst, a Mo complex featuring a sterically protected substrate-binding site (see Figure 3) initially invigorated the debate to determine the binding site of FeMoco [21]. Nishibayashi has reported pincer-based monomeric and dimeric Mo complexes, which catalytically reduce $\mathrm{N}_{2}[28,29]$. A pincer motif was later used by the same group to develop a catalytically active Fe-centered complex as well [30]. The Peters research group has published a series of Fe complexes featuring a tripodal ligand set with various axial donor atoms. The Si-ligated complex was first shown to bind $\mathrm{N}_{2}$, followed by reports of B-ligated and C-ligated complexes that could catalytically perform the reduction [22,31,32]. Spectroscopic and mechanistic studies with these compounds have demonstrated the axial donor atom modulates covalency with the Fe center throughout catalysis to support the various oxidation states and substrate coordination modes. Results from these studies were used to hypothesize a stabilizing role for the central carbide in FeMoco, performing similar modulations throughout turnover. The proposed hybrid distal-alternating mechanism determined for Peters' compounds was similarly extended to FeMoco as a possible mechanistic pathway [33]. Moreover, the tripodal donor set was later adapted to include a structurally relevant $\mathrm{S}$ donor as a bridging thiolate [34]. Synthetic work pursued by the Holland group has demonstrated activation of dinitrogen by multi-metallic cooperation between two or four iron sites, presenting biomimetic complexes for the di-iron activation of $\mathrm{N}_{2}$ displayed in the Ribbe and 
Hu crystal structure [27]. Additional synthetic work with an iron-carbonyl-thiolate complex utilizes a tridentate ligand set and is capable of $\mathrm{N}_{2}$ activation [35].

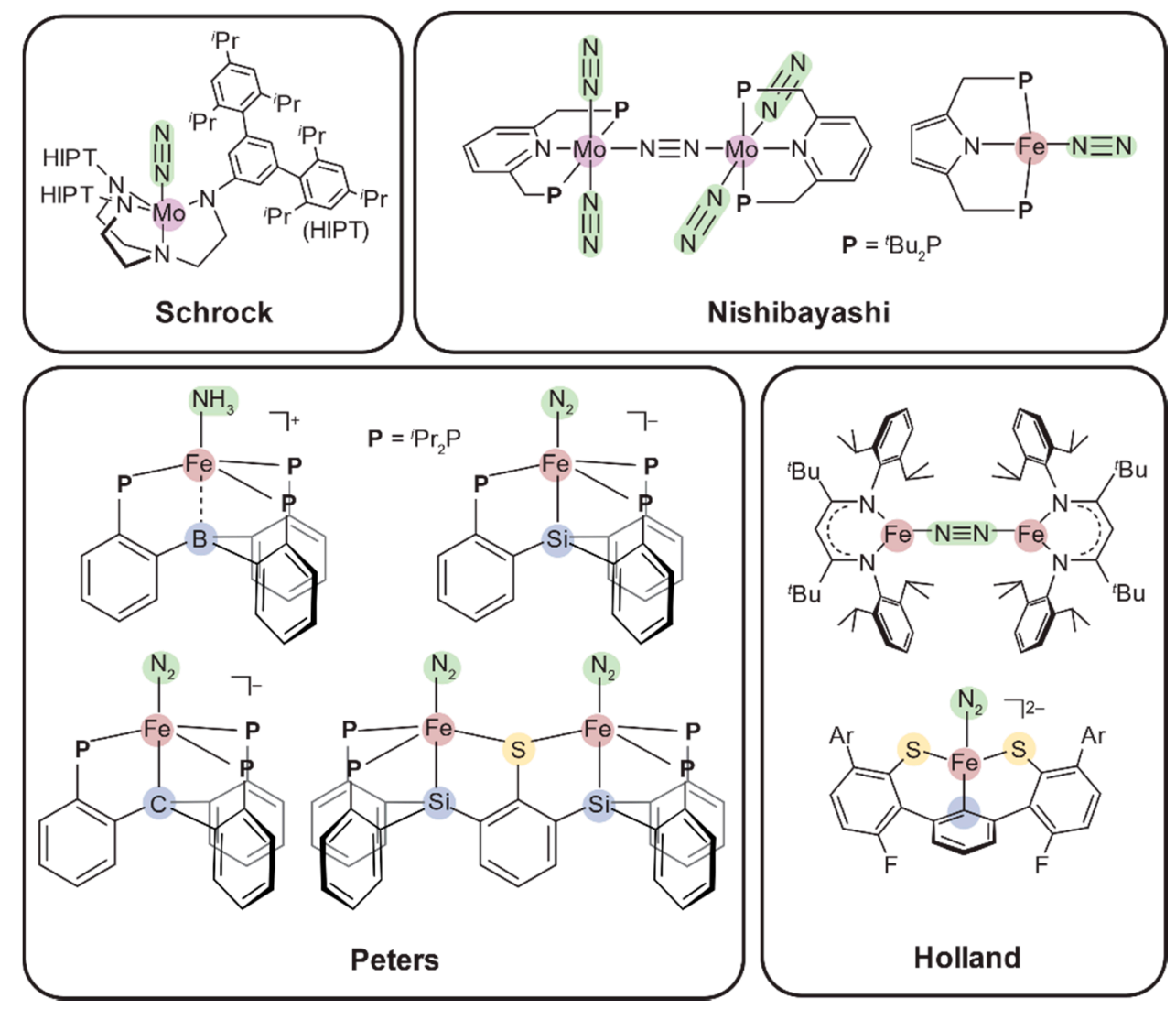

Figure 3. Selected functional synthetic compounds for $\mathrm{N}_{2}$ activation and/or reduction from the Schrock, Nishibayashi, Peters, and Holland research groups [21,22,28-35].

Functional synthetic model compounds capable of catalytically reducing or activating dinitrogen in various modes were particularly impactful toward early mechanistic discussions surrounding nitrogenase. In recent years, structural models (Figure 4) have also been extensively utilized as synthetic references in studies probing for geometric and electronic structure information about FeMoco and FeVco. The carbonyl-supported hexa-iron cluster $\left[\mathrm{Fe}_{6}\left(\mu_{6}-\mathrm{C}\right)(\mathrm{CO})_{16}\right]^{2-}$-which contains an interstitial, 6-coordinate carbide and has been featured prominently throughout our own research program-was utilized along with its nitride congener $\left[\mathrm{Fe}_{6}\left(\mu_{6}-\mathrm{N}\right)(\mathrm{CO})_{16}\right]^{-}$as a means of calibrating X-ray emission spectra to distinguish between $2 p$ atoms in multi-metallic frameworks, thereby, setting the stage for identification of the interstitial carbide in FeMoco [9].

In many respects, FeMoco is structurally similar to other synthetic and biological iron sulfur clusters. The average $\mathrm{Fe}-\mathrm{Fe}$ distance of $2.63 \pm 0.04 \AA$ places individual iron sites within the range to induce a bonding interaction between metal centers. Similarly, the average Fe-Mo distance of $2.684 \pm 0.008 \AA$ is typical for reported synthetic heterometal-iron-sulfur clusters [36]. Fe-S contacts exhibit an average distance of $2.25 \pm 0.03 \AA$ A. Finally, the Fe-C bond is not a known motif in iron-sulfur clusters outside of the nitrogenases. Moreover, synthetic iron-sulfur clusters found in the Cambridge Structural Database (CSD) do feature Fe-coordinated $\mathrm{N}$ and $\mathrm{O}$ sites, but examples with carbon have remained elusive. Nonetheless, the average Fe-C distance of $2.00 \pm 0.02 \AA$ observed in FeMoco fall within the range of distances displayed in compounds with $\mathrm{N}$ (Fe-N range: 1.871-1.977 $\AA$ ) or O (Fe-O range: $2.052-2.190 \AA$ ) incorporated donor atoms. Synthetic iron sulfur clusters developed by the Holm group and featuring heterometallic $\mathrm{Mo}^{3+}$ and $\mathrm{V}^{3+}$ sites assisted in the assignment of spin states at individual metal sites in the resting-state M-clusters and V-clusters [37-39]. Notable work by the Agapie group has demonstrated 
electronic and catalytic modulation of iron cluster sites performed by substitution of various interstitial light atoms (O, F) [40,41]. Synthetic structural modelling work from the Tatsumi group has presented a highly-relevant dicuboidal, vanadium-containing FeS cluster and an astonishingly remarkable cluster featuring belt-thiolates and an interstitial oxide [42,43]. Remarkably, Rauchfuss has recently published the first known multi-iron cluster to feature an interstitial carbide and one or multiple inorganic sulfides $[44,45]$.
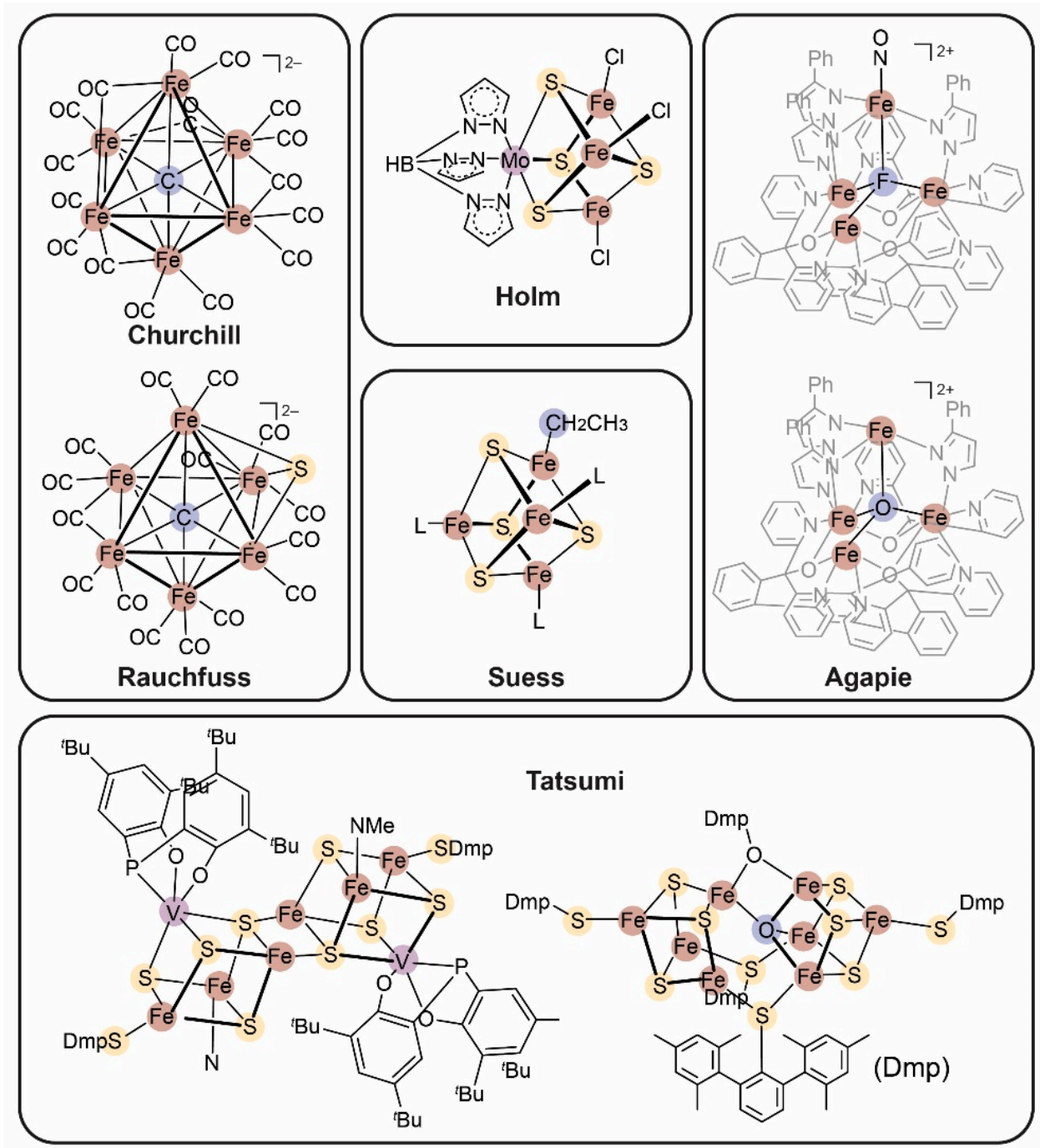

Figure 4. Selected synthetic structural models for the nitrogenase active site, including works published by the Holm, Agapie, Tatsumi, and Rauchfuss [37,38,40-49].

Synthetic development of mono-metallic and bimetallic iron complexes with C-donors is of potential importance for understanding the role of the $\mathrm{Fe}-\mathrm{C}$ bond in controlling the electronic interactions between the metal sites in FeMoco. These complexes can be isolated with low-coordinate, high-spin ferrous, and ferric iron centers such as the complexes reported by Power, Fürstner, and Re [50-52]. Additionally, Yogendra et al. recently reported a set of dimeric, yldiide-bridged iron complexes accessed from the known monomers. Magnetic susceptibility and spectroscopic studies of these dimers show intense antiferromagnetic coupling between iron sites and pronounced negative charge localization on the $C$ ligand [53]. The Holland group reported a series of $\beta$-diketiminate complexes with various bridging C-donors. Among these, an alkylidene-bridged and sulfide-bridged dimer was shown to be competent toward $\mathrm{N}_{2}$ to $\mathrm{NH}_{4}{ }^{+}$conversion with dissociation of the sulfide ligand. 
The presence of the carbon donor ligand ostensibly facilitates improvement of the $\mathrm{N}_{2}$ reduction activity of the complex along with sulfide lability [54].

An alkyl-ligated $\mathrm{Fe}_{4} \mathrm{~S}_{4}$ cluster published by Suess et al. demonstrates the dramatic electronic shift enforced upon the cubane cluster by the coordination of the electron-donating $\mathrm{R}$ group [48]. Notably, a variety of new tripodal chelating ligands were employed to enforce 3:1 site differentiation and stabilize a range of alkylated cluster oxidation states (Figure 5) [48,49]. The success and versatility of their approach represent new progress in the rational control of multi-metallic cluster chemistry, for which the ligand-control toolbox has historically been limited compared to monometallic and bimetallic inorganic synthetic work. As such, these findings open new doors toward modeling and understanding $\mathrm{Fe}_{4} \mathrm{~S}_{4}$-alkyl intermediates of enzyme active site clusters, especially the radical SAM family [55].
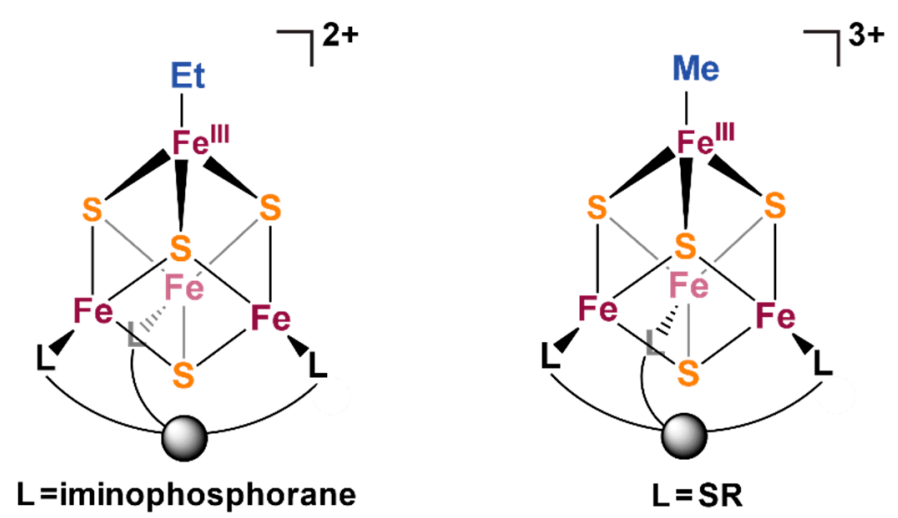

Figure $5 . \mathrm{Fe}_{4} \mathrm{~S}_{4}$-alkyl clusters stabilized by chelating tripodal ligand scaffolds recently reported by Suess et al.

\subsection{A Two-Fold Strategy toward Achieving FeMoco Construction}

Undoubtedly, the field of structural modelling in the context of nitrogenase has been invaluable in advancing the structural, electronic, and mechanistic understanding of the nitrogenase active site. However, much synthetic work remains unaccomplished. As of this writing, the synthetic 'Holy Grail' for FeMoco modeling of achieving a paramagnetic iron cluster with sulfides/thiolates, and interstitial carbide continues to be pursued. Additionally, synthetic modelling work applied to the FeMoco biogenesis-such as the intermediate steps involved in carbide formation-are scarce if not absent completely. Through the work summarized in this perspective, we sought to expand upon the compendium of structural models in progression toward incorporation of important structural and electronic attributes of FeMoco (Figure 6) into synthetic clusters.

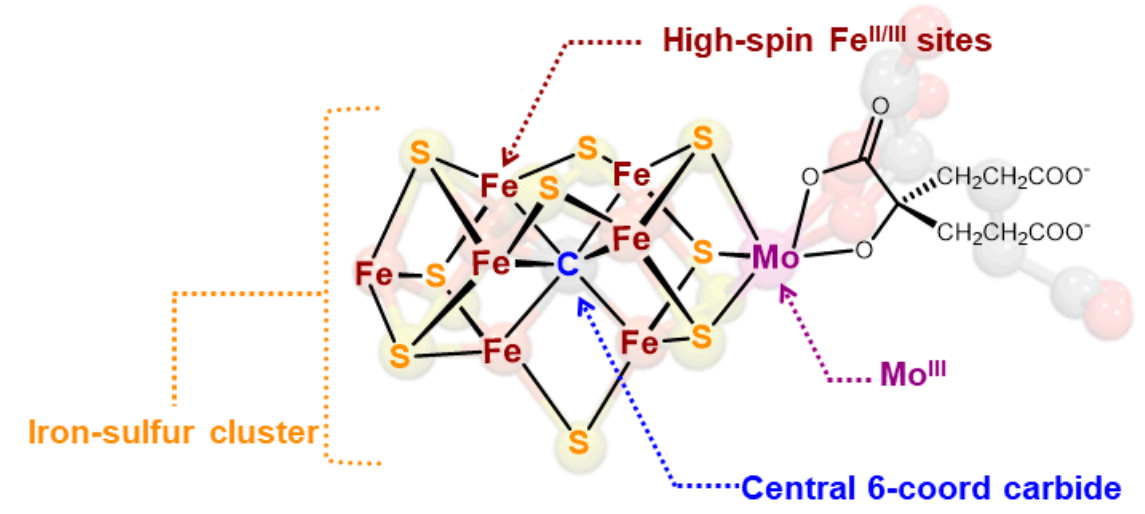

Figure 6. Target structural and electronic attributes of interest in FeMoco for biomimetic modelling. 
To this end, a two-fold strategy was employed in our nitrogenase biomimetics research program (Scheme 1). First, we took inspiration from the biomechanistic pathway proposed by Ribbe and $\mathrm{Hu}$ for FeMoco biogenesis. A carbonyl-supported iron sulfide cluster $\mathrm{K}_{2}\left[\mathrm{Fe}_{3} \mathrm{~S}(\mathrm{CO})_{9}\right]$ was synthesized and alkylated with various alkyl halides $\left(\mathrm{R}=\mathrm{Me},{ }^{\mathrm{i}} \mathrm{Pr}, \mathrm{Bz}\right)$. The resulting $\mu_{3}$-thiolato cluster was subsequently treated with a radical initiator TEMPO ((2,2,6,6-tetramethylpiperidin-1-yl)oxyl) to emulate the $\mathrm{H}$ atom abstraction mechanism propagated by SAM upon the K cluster. We additionally pursued a converse strategy utilizing a family of carbonyl-supported iron clusters featuring interstitial carbides-the first of which was reported by Braye et al. in 1962 [56]. The hexa-iron cluster $\left(\mathrm{NEt}_{4}\right)_{2}\left[\mathrm{Fe}_{6}\left(\mu_{6}-\mathrm{C}\right)(\mathrm{CO})_{16}\right]$ reported by Churchill et al. [46,47] serves as a synthetic starting point toward highly FeMoco-relevant structural models, demonstrating flexibility between multiple redox states and versatility for heterometal substitution and sulfide incorporation $[44,57,58]$. Here, a strategy was explored for ligand $\mathrm{CO} \rightarrow \mathrm{S}$ substitution by using electrophilic sulfur upon the soft anionic clusters.

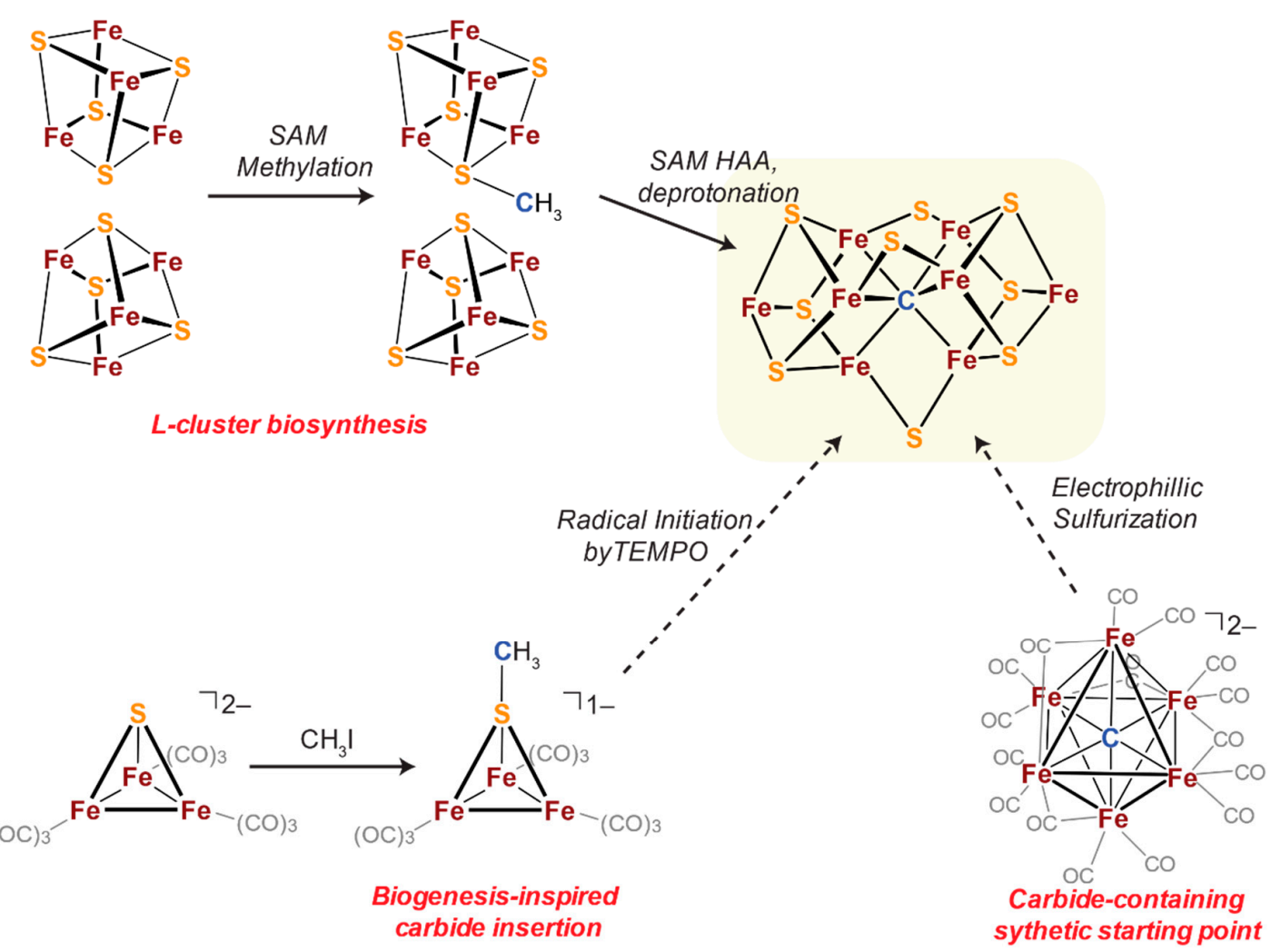

Scheme 1. A two-fold synthetic approach toward achieving structural analogues of the L-cluster, precursor to FeMoco. First, inspiration was taken from the biosynthetic conversion of the K-cluster $\left(2 \times \mathrm{Fe}_{4} \mathrm{~S}_{4}\right)$ to the L-cluster $\left(\mathrm{Fe}_{8} \mathrm{~S}_{9} \mathrm{C}\right)$ by NifB. As such, a methyl group was installed upon an $\mathrm{Fe}_{3} \mathrm{~S}$ cluster using MeI. TEMPO was then utilized as a radical initiator to emulate similar radical abstraction of hydrogen observed during L-cluster synthesis. Alternatively, an anionic $\mathrm{Fe}_{6} \mathrm{C}$ cluster featuring an interstitial carbide was found to be a useful synthetic starting point for sulfur incorporation via electrophilic sulfur reagents.

\section{Synthetic Manipulations of CO-Supported FeS and FeC Clusters}

\subsection{Biogenesis-Inspired Approach to FeSC Cluster Construction}

As discussed above, the biogenesis of the M-cluster in nitrogenase has garnered much interest since the identification of the interstitial carbide in 2011 [7,8]. The unique motif of a 6-coordinate $C^{4-}$ bound to the six iron centers present in $\mathrm{FeMoco} / \mathrm{FeVco}$ are the only reported examples in biological systems [59]. It is highly likely, however, that the all-iron analogue of the enzyme also contains 
a carbide. Few examples exist in chemical systems as well with the notable exception of the synthetic carbide clusters (vide infra).

It was shown that carbide formation at the K-cluster requires two equivalents of SAM including one for the methyl group donation (which eventually becomes the carbide) and a second one for the radical abstraction of a hydrogen atom [11]. The initial binding site of the methyl group was also traced by liquid and gas chromatographic methods HPLC and GCMS, revealing that the methyl group first binds to a sulfide in the native enzyme [12]. This is counterintuitive, as one would expect an all-iron ligated carbide to initially bind to an iron center. However, biological Fe oxidation states are likely not nucleophilic enough to form $\mathrm{Fe}-\mathrm{C}$ bonds. Considering this, it is then understandable that nitrogenase utilizes a radical mechanism for carbide formation. Furthermore, the proposed mechanism indicates that transfer of the methyl group occurs prior to radical $\mathrm{H}$ atom abstraction and subsequent deprotonation/dehydrogenation.

These results provided the stimulus for our initial biomimetic approach for investigating the reactivity of methyl-substituted iron-sulfur clusters with a radical initiator. The synthetic cluster $\mathrm{K}_{2}\left[\left(\mu_{3}-\mathrm{S}\right) \mathrm{Fe}_{3}(\mathrm{CO})_{9}\right]$ (Scheme 2 ) was chosen due to its versatility in substituting R groups using common electrophiles that can be installed on the $S^{2-}$ 'bridgehead,' making it a suitable model system for investigating $-\mathrm{SCH}_{3}$ reaction mechanisms associated with iron-containing clusters. The methylation of $\mathrm{K}_{2}\left[\mathrm{SFe}_{3}(\mathrm{CO})_{9}\right]$ was achieved by a reaction with $\mathrm{CH}_{3} \mathrm{I}$ in THF at $0{ }^{\circ} \mathrm{C}$, affording the monoanionic $\mathrm{K}\left[\left(\mathrm{CH}_{3} \mathrm{~S}\right) \mathrm{Fe}_{3}(\mathrm{CO})_{9}\right](\mathbf{1})$. The resulting bond metrics were similar to those previously observed in $\mathrm{NEt}_{4}\left[\left(\mathrm{CH}_{3} \mathrm{~S}\right) \mathrm{Fe}_{3}(\mathrm{CO})_{9}\right]$ [60]. It would be expected that radical hydrogen abstraction reagents would readily abstract an $\mathrm{H}$-atom from the anion. However, because the low valent Fe clusters typically demonstrate a proclivity toward forming bridging hydrides, we elected to utilize a relatively mild $\mathrm{H}$-atom abstraction reagent. Thus, (2,2,6,6-tetramethylpiperidin-1-yl)oxyl (TEMPO) was selected due to its mild $\mathrm{O}-\mathrm{H}$ bond dissociation energy [61].

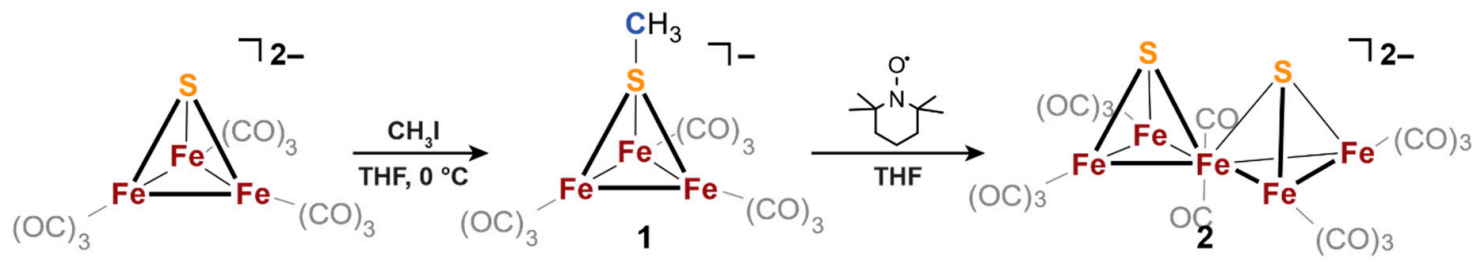

Scheme 2. Synthetic scheme depicting the formation of 1 and its reaction with the radical initiator, TEMPO, to form 2.

The reaction of the methylated $\mathrm{Fe}_{3} \mathrm{~S}$ cluster and crystallization of the charged portion revealed an aggregation product in which the methyl group had been displaced, yielding the formula $\left.[\mathrm{K} \text { (benzo-15-crown-5 })_{2}\right]_{2}\left[\left(\mathrm{SFe}_{2}(\mathrm{CO})_{12}\right)_{2} \mathrm{Fe}(\mathrm{CO})_{2}\right](2)$. This reactivity indicated the occurrence of two key transformations: (i) $\mathrm{S}-\mathrm{CH}_{3}$ bond breakage to generate the inorganic sulfide, and (ii) the combination of two $\mathrm{Fe}_{3}$ units (and extrusion of one Fe center) to form an $\mathrm{S}_{2} \mathrm{Fe}_{5}$ framework. Additionally, two-electron oxidation of the Fe centers was observed (one electron from each progenitor cluster of $\mathbf{1}$ ). The resultant formation of $\mathbf{2}$ is unaffected by dramatic changes in reaction conditions including solvent identity (THF, $\mathrm{MeCN}, \mathrm{FPh})$ or temperature $\left(-78^{\circ} \mathrm{C}\right.$ or ambient temperature), showcasing the low kinetic barrier present in reactions with these types of iron clusters such that the same thermodynamically stable product is recurringly generated, highlighting the uniqueness of the biogenesis in FeMoco assembly.

This process does bear some resemblance to the biosynthesis of the FeMoco active site, wherein the addition of SAM causes oxidation of the SAM-motif-bound $\left[\mathrm{Fe}_{4} \mathrm{~S}_{4}\right]^{1+}$ in NifB to an oxidized EPR silent intermediate [62]. In this process, $\mathrm{S}^{2-}$ and $\mathrm{C}^{4-}$ are ultimately generated as charged ligands, implying oxidation of the iron centers en route to the intermediate L cluster. Unfortunately, the incorporation of any carbon (or carbide) motif to the synthetic cluster $\mathbf{1}$ was not observed in the generation of $\mathbf{2}$, even though it was demonstrated that a radical electron can aid in the fusion of two iron-sulfur units and aid in the gradual oxidation of the Fe centers. 


\subsection{Sulfide Incorporation into Iron-Carbide Clusters: Initial Attempts}

Our initial foray into ligand substitution upon $\left(\mathrm{NEt}_{4}\right)_{2}\left[\mathrm{Fe}_{6}\left(\mu_{6}-\mathrm{C}\right)(\mathrm{CO})_{16}\right]$ began with the utilization of a bidentate, anthracene-scaffolded bis-phenylthiolate ligand set (Scheme 3). The choice of the anthracene scaffold was motivated by the observation that the $5.1 \AA$ distance between the 1 and 8 positions on the anthracene backbone closely correlated with the $5.0 \AA$ A $\mathrm{S}$...S distance between distal sulfide sites in FeMoco. However, treatment of the $\left[\mathrm{Fe}_{6} \mathrm{C}\right]^{2-}$ cluster with disodium 1,8-bis(phenylthiolato) anthracene does not induce any color change in the reaction mixture (Scheme 4). In 2015, Figueroa et al. reported on isocyanide analogues of iron carbonyls, noting that isocyanides-similar to carbonyls-act as excellent $\pi$-acceptors, but additionally exhibit stronger $\sigma$-donating ability relative to carbon monoxide. This increases the reactivity of their host metal toward substrates including $\mathrm{N}_{2}$ [63]. Following this line of research, $\left[\mathrm{Fe}_{6} \mathrm{C}\right]^{2-}$ was treated with 2,6-dimethylphenyl isocyanide, resulting in a reaction solution dominated by a dark green color-indicative of decomposition to $\mathrm{Fe}_{3}(\mathrm{CO})_{12}$ and other intractable products.
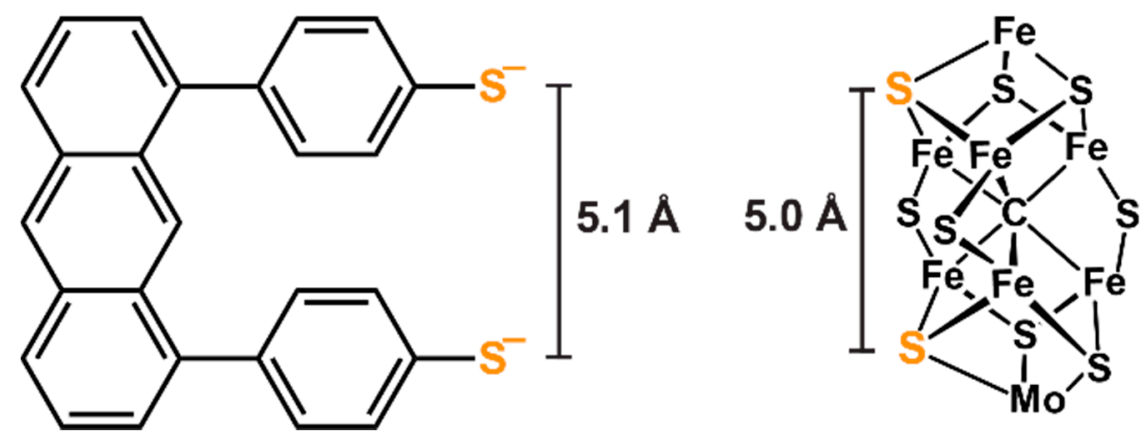

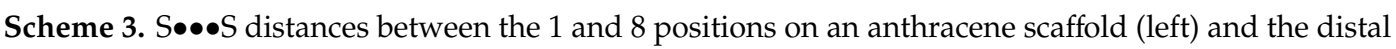
sulfides in FeMoco (right).

Another attempted effort to incorporate sulfur into carbidocarbonyl iron cluster was in the direct reaction of the nido- $\mathrm{Fe}_{5}$ neutral cluster $\left[\mathrm{Fe}_{5}\left(\mu_{5}-\mathrm{C}\right)(\mathrm{CO})_{15}\right]$ with elemental sulfur $\left(\mathrm{S}_{8}\right)$. However, performing the reaction at room temperature or $60^{\circ} \mathrm{C}$ results in the formation of a small amount of an insoluble and ferromagnetic black powder (presumably metallic iron) and an unconverted $\left[\mathrm{Fe}_{5} \mathrm{C}\right]^{0}$ band. Increasing the temperature to $90{ }^{\circ} \mathrm{C}$ significantly decomposes $\left[\mathrm{Fe}_{5} \mathrm{C}\right]^{0}$ into the same black powder, and reaction at $120^{\circ} \mathrm{C}$ results in total decomposition. Alternatively, a literature report found that elements from the pnictogen series were successfully reacted with $\left[\mathrm{Fe}_{5} \mathrm{C}\right]^{0}$ in the presence of $\mathrm{H}_{2} \mathrm{SO}_{4}$ at $100{ }^{\circ} \mathrm{C}$ for $30 \mathrm{~min}$ to generate a tri-iron methylidene cluster with the formula $\mathrm{Fe}_{3}\left(\mu_{3}-\mathrm{CH}\right) \mathrm{E}(\mathrm{CO})_{9}$ $(\mathrm{E}=\mathrm{As}, \mathrm{Sb}, \mathrm{Bi})[64]$. Elemental arsenic and bismuth were found to work for this reaction. Interestingly, the $\mathrm{Sb}$ cluster could only be achieved with $\mathrm{SbCl}_{5}$. Efforts to replicate these conditions with elemental sulfur produced a dark red-orange solution, which afforded only crystals of the non-carbide-containing cluster $\mathrm{Fe}_{3} \mathrm{~S}_{2}(\mathrm{CO})_{9}$. Similarly, using selenium powder under the same conditions gave crystals of $\mathrm{Fe}_{3} \mathrm{Se}_{2}(\mathrm{CO})_{9}$.

Finally, the utilization of triphenyl antimony sulfide $\left(\mathrm{Ph}_{3} \mathrm{Sb}=\mathrm{S}\right)$ as a thermoneutral sulfur atom donor was considered due to its behavior as a weak sulfur-donating ability and the absence of S-S bonds such as those seen in elemental sulfur (Scheme 5) [65]. Preparation of the reagent for the in situ and transfer into an ice-cold toluene suspension of $\left[\mathrm{Fe}_{6} \mathrm{C}\right]^{2-}$ resulted in a highly convoluted mixture of compounds, thereby obstructing the growth of crystals suitable for $\mathrm{X}$-ray diffraction. 

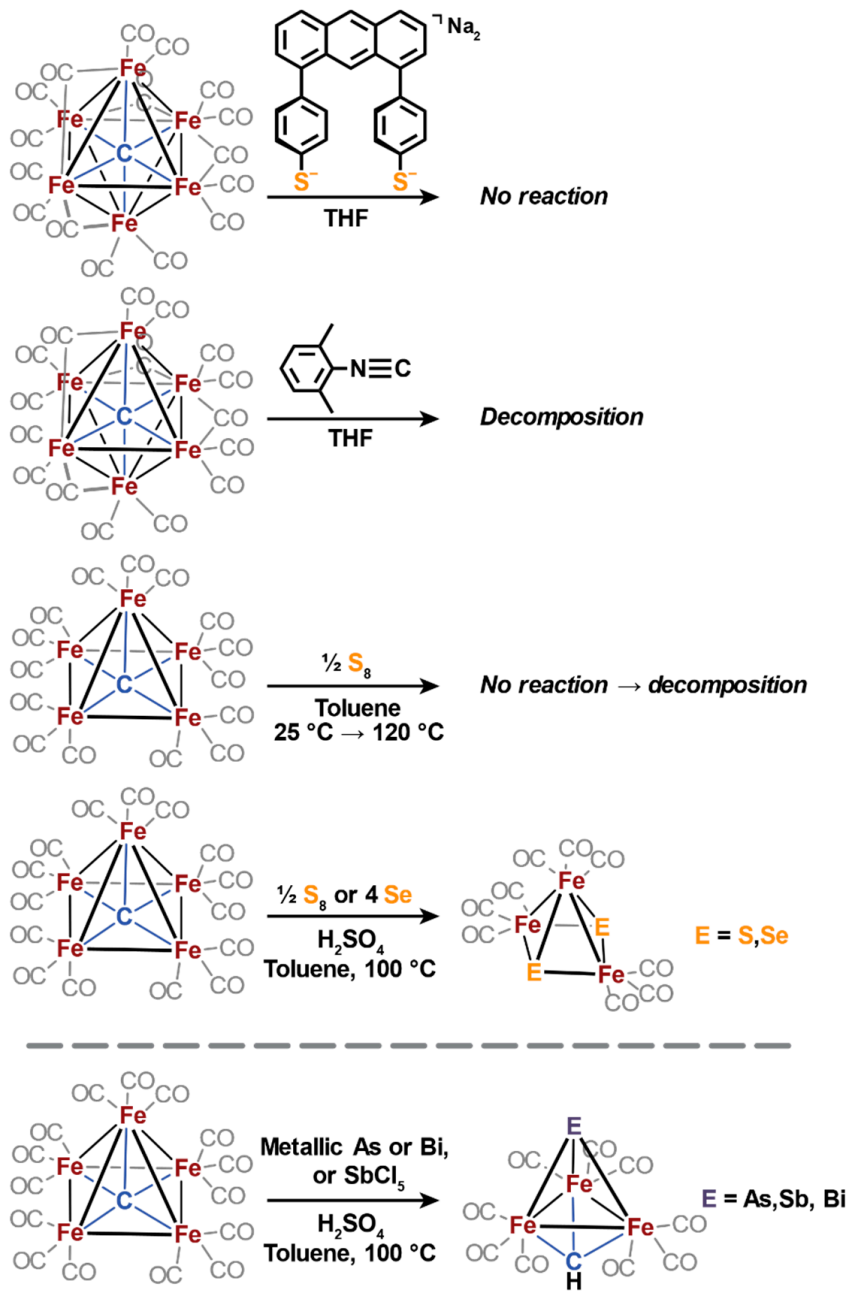

Scheme 4. Various reaction conditions attempted to pursue controlled ligand substitution onto iron carbide clusters (top) and schematic representation of reaction conditions reported in Reference [64] (bottom).
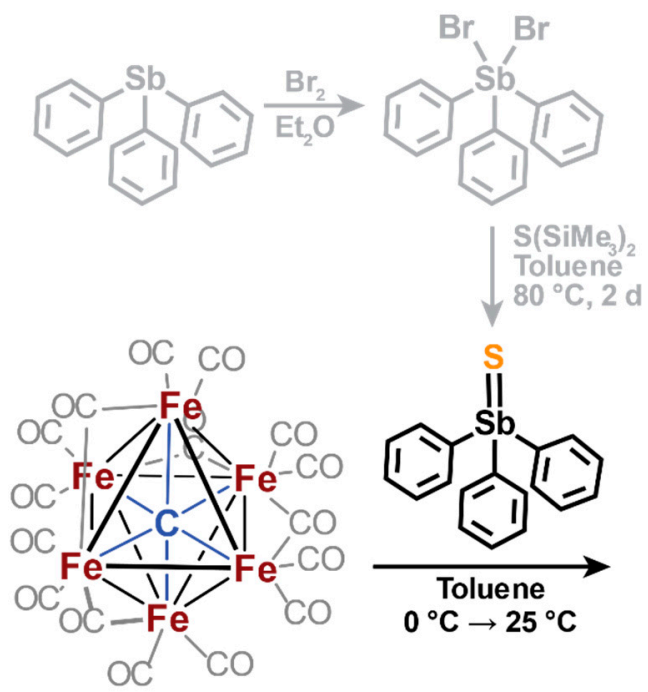

Multiple products

Scheme 5. In situ synthesis of triphenyl antimony sulfide and reaction conditions for sulfur donation into $\left[\mathrm{Fe}_{6} \mathrm{C}\right]^{2-}$ cluster. 


\subsection{Electrophilic Sulfur Sources: Isolation of Sulfide-Containing Carbidocabonyl Iron Clusters}

Because of the undesirable results obtained from using conventional Lewis basic ligands (sulfides, thiolates) with the anionic and neutral iron clusters, we sought an alternative strategy for achieving sulfide incorporation. At the time, the only report of successful ligation by a sulfur-based donation set upon carbidocarbonyl iron clusters was a 1988 publication by Shriver et al. describing the synthesis and isolation of $\mathrm{SO}_{2}$-ligated $\mathrm{Fe}_{6}$ and $\mathrm{Fe}_{5}$ clusters [66]. However, the use of these $\mathrm{SO}_{2}$ clusters as isolable intermediates in pursuit of a sulfide-ligated iron-carbide clusters was a suspected 'dead-end' in the absence of a strategy for successful reduction and oxide removal from $\mathrm{SO}_{2}$. We do note, however, that Rauchfuss et al. has reported achievement of an S-ligated cluster via an $\mathrm{SO}_{2}$ intermediate [44]. Nonetheless, the observation that, upon ligation, $\mathrm{SO}_{2}$ behaves electrophilically (therefore, oxidizing the anionic cluster) and the additional observation that the gallery of reported heteroleptic carbidocarbonyl iron clusters in the CSD feature initial oxidation prior to ligand incorporation $\left(\mathrm{NO}, \mathrm{H}^{+} \rightarrow \mathrm{H}^{-}\right.$, Lewis acidic $\mathrm{Cu}$-, and Au-bearing reagents) [36] prompted us to seek out similarly electrophilic sulfur-based ligand sets.

As such, a synthetic strategy centered around $\mathrm{S}_{2} \mathrm{Cl}_{2}$ was deemed appropriate for sulfide incorporation [67]. While $\mathrm{SCl}_{2}$ is more structurally analogous to $\mathrm{SO}_{2}$ (Figure 7), the reported instability of the reagent and its spontaneous conversion to $\mathrm{S}_{2} \mathrm{Cl}_{2}$ marked it as less preferable. Treatment of the hexa-nuclear cluster $\left(\mathrm{NEt}_{4}\right)_{2}\left[\mathrm{Fe}_{6}\left(\mu_{6}-\mathrm{C}\right)(\mathrm{CO})_{16}\right]$ with $\mathrm{S}_{2} \mathrm{Cl}_{2}$ afforded a mixture of products (Scheme 6). We initially characterized the asymmetric, sulfide-bridged 'dimer of clusters' $\left(\mathrm{NEt}_{4}\right)_{2}\left\{\left[(\mathrm{CO})_{15}\left(\mu_{6}-\mathrm{C}\right) \mathrm{Fe}_{6}\right]\left(\mu_{4}-\mathrm{S}\right)\left[\mathrm{Fe}_{5}\left(\mu_{5}-\mathrm{C}\right)(\mathrm{CO})_{13}\right]\right\}$ (3). The dimer was structurally identified by XRD as featuring a four-coordinate bridging sulfide tethered between a six-iron and a five-iron cluster including each cluster with an interstitial carbide. Crystal structure data (Figure 8) reveals Fe-S distances [2.203(3), 2.189(3), 2.188(3), 2.169(2) Å] that are noticeably short for a CO supported $\left\{\mathrm{Fe}_{2}\left(\mu_{4}-\mathrm{S}\right) \mathrm{Fe}_{2}\right\}$ motif. Exploration of this motif in the CSD [36] produces an average of $2.25 \pm 0.01 \AA$. The average Fe-S bond distance of $2.19 \pm 0.01 \AA$ in 3 is, thus, remarkably short. The longest bond length in 3 at 2.203(3) $\AA$ is shorter than the shortest recorded CSD Fe-S bond (2.215 $\AA$ ) in an $\left\{\mathrm{Fe}_{2}\left(\mu_{4}-\mathrm{S}\right) \mathrm{Fe}_{2}\right\}$ motif. In comparison to the bond metrics found in FeMoco [68], the Fe-S bond falls short of the average Fe-S bond found in the active site $(2.25 \pm 0.03 \AA)$. The average Fe-Fe bond distance of $2.65 \pm 0.06 \AA$ in 3 is unremarkable. Thus, the presence of the sulfide does not induce any notable elongation or compression of Fe-Fe bond lengths in $\mathrm{Fe}_{5}-\mathrm{Fe}_{8}$. The average $\mathrm{Fe}-\mathrm{C}$ bond distance in the six-iron unit of cluster 3 is $1.89 \pm 0.01 \AA$ when compared to $1.881 \pm 0.005 \AA$ in the published $\mathrm{Fe}_{6}$ cluster [57]. In the 5-iron unit of cluster 3 , the equatorial iron sites average an $\mathrm{Fe}-\mathrm{C}$ bond distance of $1.86 \pm 0.01 \AA$, while the axial iron resides at an elongated bond distance of 1.95(1) $\AA$. This is strikingly similar to the published $\mathrm{Fe}_{5}$ neutral cluster $\left[\left(\mathrm{Fe}_{\mathrm{eq}}-\mathrm{C}_{\mathrm{avg}}=1.88 \pm 0.02 \AA ; \mathrm{Fe}_{\mathrm{ax}}-\mathrm{C}=1.949(7) \AA\right]\right.$. The $\mathrm{Fe}-\mathrm{C}$ bonds found in 3, however, are shorter than the FeMoco average of $2.00 \pm 0.02 \AA$.

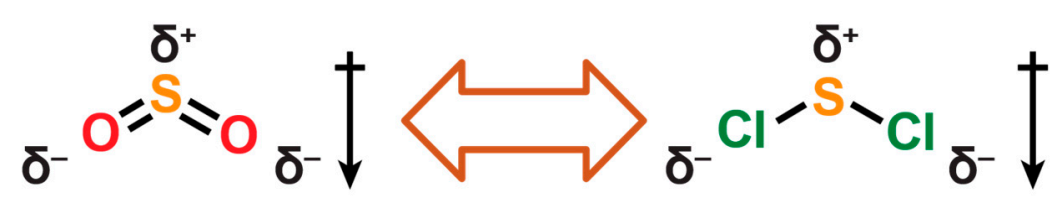

Figure 7. Schematic indication of the dipole in electropositive sulfur reagents. 


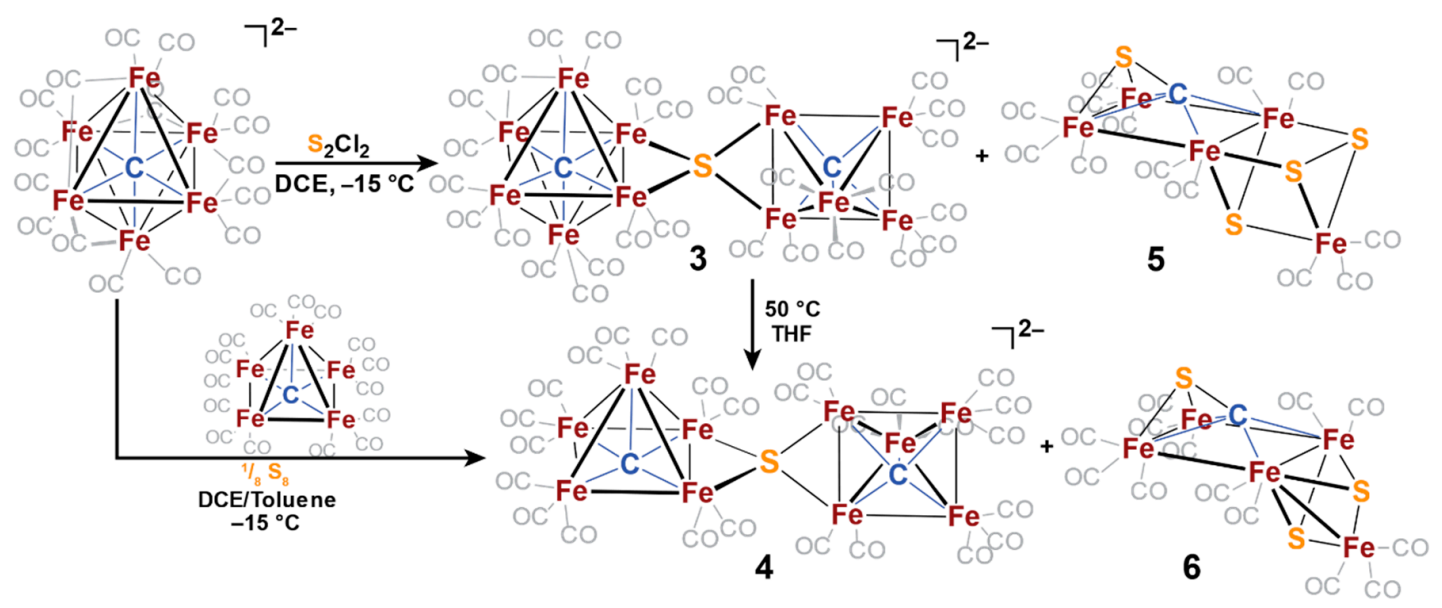

Scheme 6. Synthetic scheme depicting the electrophilic sulfurization of the $\mathrm{Fe}_{6} \mathrm{C}$ dianion cluster by either $\mathrm{S}_{2} \mathrm{Cl}_{2}$ or elemental sulfur to afford a $\mu_{4}-\mathrm{S}$ cluster ( 3 or 4 ) and a $\{\mathrm{CS}\}^{4-}$ cluster ( 5 or 6 ). The non-carbide cluster $\left[\mathrm{Fe}_{3} \mathrm{~S}_{2}(\mathrm{CO})_{9}\right]$ (not depicted) was also characterized as a side product in both reactions. Image adapted with permission from Joseph, C., Cobb, C. R., Rose, M. J. Single-Step Insertion of Sulfides and Thiolate into Iron Carbide-Carbonyl Clusters: Unlocking the Synthetic Door to FeMoco Analogues. Angew. Chemie Int. Ed. 2020, Accepted, not yet published. Copyright Wiley-VCH GmbH. Reproduced with permission.

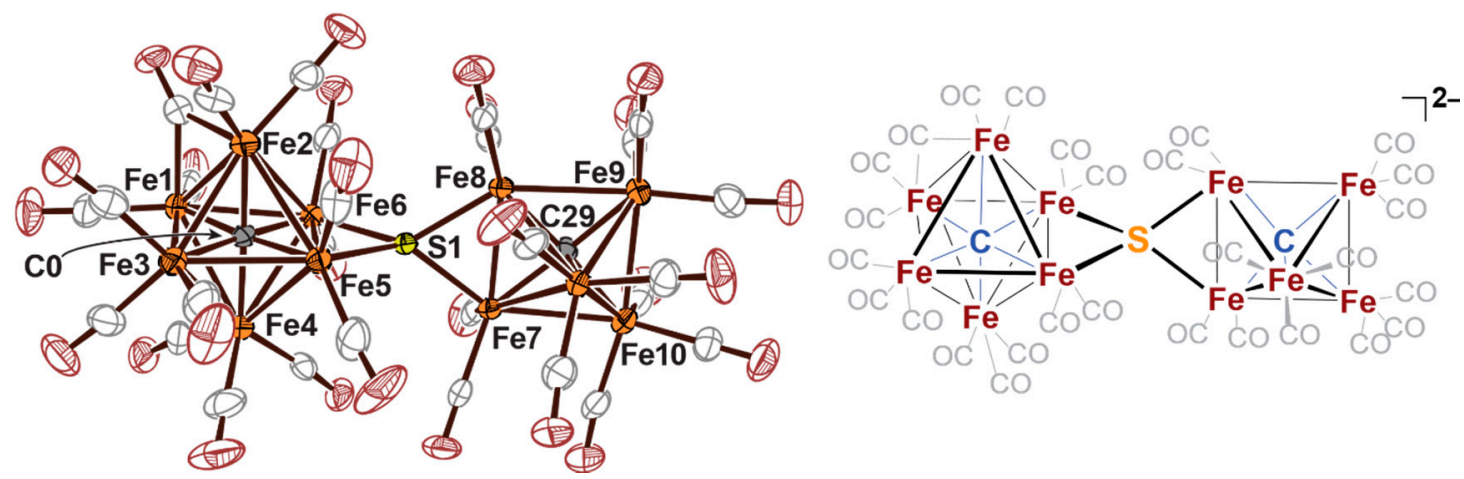

Figure 8. Thermal ellipsoid plots (50\% probability) of $\left(\mathrm{NEt}_{4}\right)_{2}\left\{\left[(\mathrm{CO})_{15}\left(\mu_{6}-\mathrm{C}\right) \mathrm{Fe}_{6}\right]\left(\mu_{4}-\mathrm{S}\right)\left[\mathrm{Fe}_{5}\left(\mu_{5}-\mathrm{C}\right)(\mathrm{CO})_{13}\right]\right\}$ (3). Orange $=\mathrm{Fe}$, Gray $=\mathrm{C}$, Yellow $=\mathrm{S}$, Maroon $=\mathrm{O}$. $\mathrm{Two} \mathrm{NEt}_{4}{ }^{+}$cations have been removed for clarity. Image adapted with permission from Joseph, C., Cobb, C. R., Rose, M. J. Single-Step Insertion of Sulfides and Thiolate into Iron Carbide-Carbonyl Clusters: Unlocking the Synthetic Door to FeMoco Analogues. Angew. Chemie Int. Ed. 2020, Accepted, not yet published. Copyright Wiley-VCH GmbH. Reproduced with permission.

However, the generation of side products and the presence of chloride in the synthesis of the sulfide-bridged, asymmetric dimer led us to seek more straightforward reaction conditions. Since this cluster can be thematically formulated as an $\mathrm{Fe}_{6}$ cluster, an $\mathrm{Fe}_{5}$ cluster, a sulfur bridge, and an overall $2^{-}$charge, we attempted to stoichiometrically construct the compound by introducing elemental sulfur into a solution of $\left(\mathrm{Et}_{4} \mathrm{~N}\right)_{2}\left[\mathrm{Fe}_{6}\left(\mu_{6}-\mathrm{C}\right)(\mathrm{CO})_{16}\right]$ and $\left[\mathrm{Fe}_{5}\left(\mu_{5}-\mathrm{C}\right)(\mathrm{CO})_{15}\right]$. To our surprise, crystal structural data for this charged species in this reaction revealed a symmetric dimer of $\mathrm{Fe}_{5}$ clusters bridged by the same 4-coordinate sulfide motif (Figure 9) with the formula $\left(\mathrm{NEt}_{4}\right)_{2}\left\{\left[\mathrm{Fe}_{5}\left(\mu_{5}-\mathrm{C}\right)(\mathrm{CO})_{13}\right]_{2}\left(\mu_{4}-\mathrm{S}\right)\right\}(4)$. The $\mathrm{Fe}-\mathrm{C}$ bond distances of this cluster are similar to the $\mathrm{Fe}_{5}$ component of 3 , exhibiting an average $\mathrm{Fe}_{\mathrm{eq}}-\mathrm{C}$ bond distance of $1.87 \pm 0.01 \AA$ and an average $\mathrm{Fe}_{\mathrm{ax}}-\mathrm{C}$ bond distance of $1.961 \pm 0.005 \AA$. The average Fe-S distance of $2.175 \pm 0.005 \AA$, however, is notably shorter than the already short distance found in $\mathbf{3}$ and is far shorter than the Fe-S distances observed in FeMoco. 


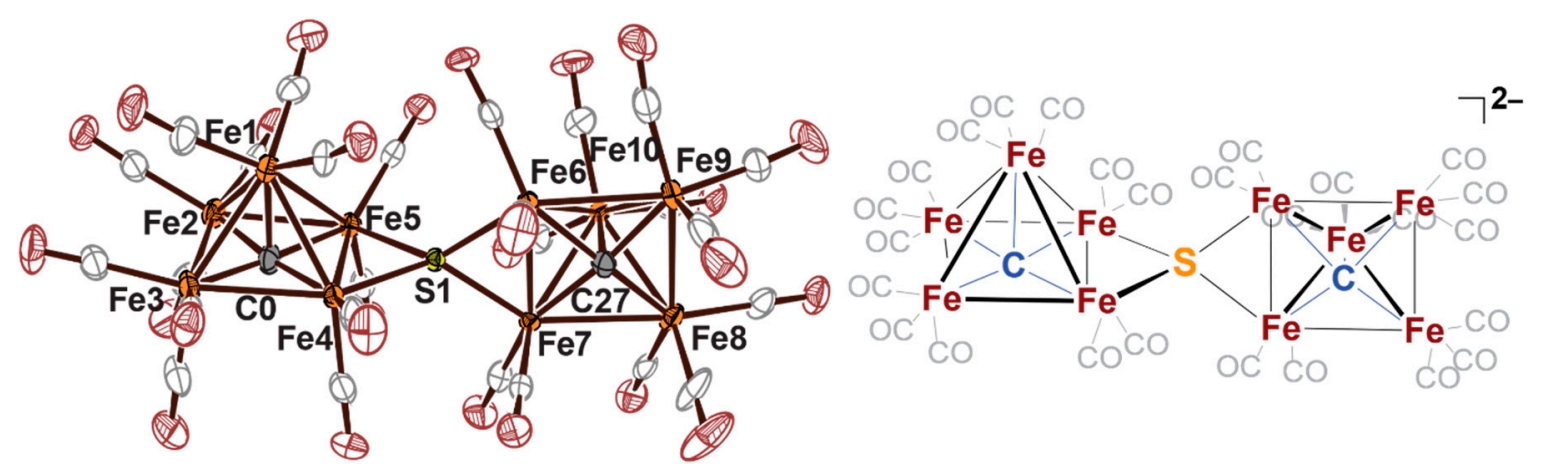

Figure 9. Thermal ellipsoid plots (50\% probability) of $\left(\mathrm{NEt}_{4}\right)_{2}\left\{\left[\mathrm{Fe}_{5}\left(\mu_{5}-\mathrm{C}\right)(\mathrm{CO})_{13}\right]_{2}\left(\mu_{4}-\mathrm{S}\right)\right\}$ (4). Orange $=\mathrm{Fe}$, Gray $=\mathrm{C}$, Yellow $=\mathrm{S}$, Maroon $=\mathrm{O}$. Two $\mathrm{NEt}_{4}{ }^{+}$cations have been removed for clarity. Image adapted with permission from Joseph, C., Cobb, C. R., Rose, M. J. Single-Step Insertion of Sulfides and Thiolate into Iron Carbide-Carbonyl Clusters: Unlocking the Synthetic Door to FeMoco Analogues. Angew. Chemie Int. Ed. 2020, Accepted, not yet published. Copyright Wiley-VCH GmbH. Reproduced with permission.

Our efforts to fully characterize the product profiles for the reactions described above prompted us to separate and purify the remaining neutral compounds. The major component of the pentane-soluble portion is a deep, bright red compound. Isolation and crystallization of the bright-red compound generated the well-known cluster $\mathrm{Fe}_{3} \mathrm{~S}_{2}(\mathrm{CO})_{9}[69,70]$. More remarkably, crystals from the red-orange $\mathrm{Et}_{2} \mathrm{O}$ solution revealed a remarkable CO-supported iron-sulfur cluster featuring a "carbide-like" site, multiple sulfur atoms, and a 'dangler' iron (Figure 10), resulting in the formula $\left[\left\{\mathrm{Fe}_{4}\left(\kappa_{2} \mathrm{~S}-\kappa_{4} \mathrm{C}\right)(\mathrm{CO})_{10}\right\}\left(\mu_{3}-\mathrm{S}\right)\left(\mu_{3}-\mathrm{S}_{2}\right) \mathrm{Fe}(\mathrm{CO})_{3}\right](5)$.

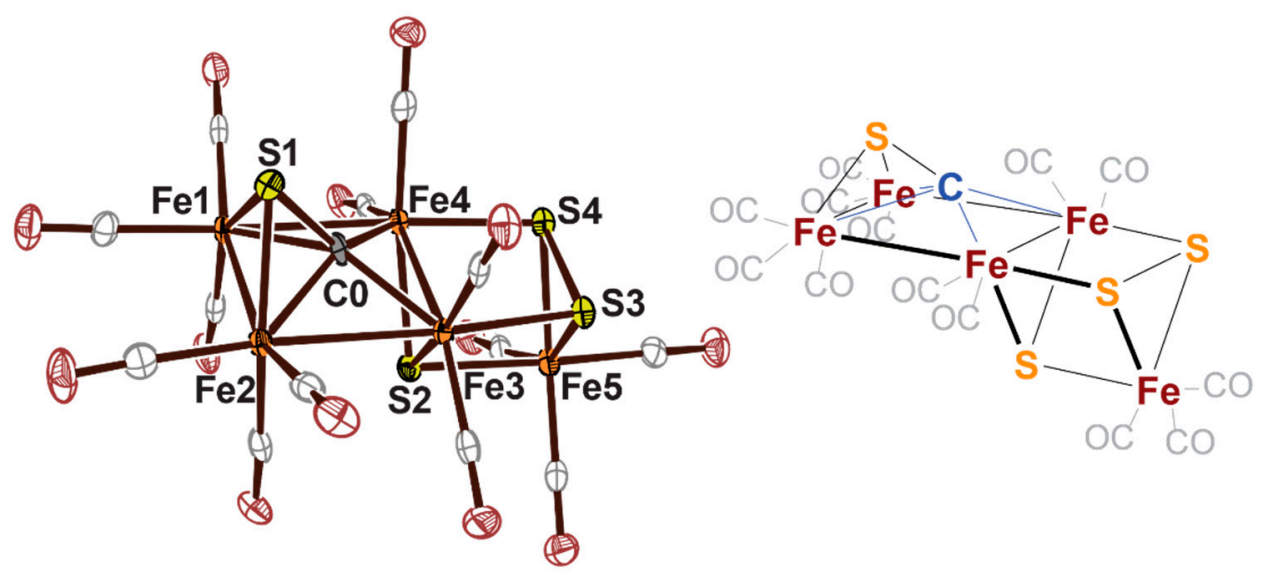

Figure 10. Thermal ellipsoid plots (50\% probability) of $\left[\left\{\mathrm{Fe}_{4}\left(\kappa_{2} \mathrm{~S}-\kappa_{4} \mathrm{C}\right)(\mathrm{CO})_{10}\right\}\left(\mu_{3}-\mathrm{S}\right)\left(\mu_{3}-\mathrm{S}_{2}\right) \mathrm{Fe}(\mathrm{CO})_{3}\right](5)$. Orange $=\mathrm{Fe}$, Gray $=\mathrm{C}$, Yellow $=\mathrm{S}$, Maroon $=$ O. Image adapted with permission from Joseph, C., Cobb, C. R., Rose, M. J. Single-Step Insertion of Sulfides and Thiolate into Iron Carbide-Carbonyl Clusters: Unlocking the Synthetic Door to FeMoco Analogues. Angew. Chemie Int. Ed. 2020, Accepted, not yet published. Copyright Wiley-VCH GmbH. Reproduced with permission.

A thorough search through the CSD for $\left\{\mathrm{Fe}_{4}\left(\mu_{4}-\mathrm{C}\right)\right\}$ motifs exclusively returns clusters in which the irons sites adopt a 'butterfly' geometry about the carbide, marking the planar geometry displayed in 5 as unique. While the average Fe-Fe bond distance ( $2.66 \pm 0.09 \AA)$ is typical of iron-carbonyl-carbide clusters, the average $\mathrm{Fe}-\mathrm{C}$ distance of $1.97 \pm 0.04 \AA$ is remarkably longer than average for this type of cluster and, instead, is very close to the average Fe-C distance found in FeMoco $(2.00 \pm 0.02 \AA)$. This elongation is - in part-an artifact of the displaced position of the carbide from the $\mathrm{Fe}_{4}$ plane, such that the carbide actually resides $0.59 \AA$ above the least-squares plane derived from the positions of the four Fe atoms. Lastly, the Fe-S distances found in $\mathbf{5}$ are notable as the average distance of 
$2.27 \pm 0.03 \AA$, which is considerably elongated when compared to 3 and 4 , placing it closer to that of FeMoco $(2.25 \pm 0.03 \AA$ ). Of particular note, if 'belt sulfides' are excluded from the FeMoco average, the similarity is even more pronounced as the average Fe-S of $2.27 \pm 0.03 \AA$ in FeMoco is exactly on par with that of 5 . Two of the $S$ sites $(S 3, S 4)$ are bonded $(2.048(2) \AA)$, resulting in the presence of a persulfide S-S bond.

Purification of the nonpolar fractions collected during the synthesis of 4 provides a related crystal structure of formula $\left[\left\{\mathrm{Fe}_{4}\left(\kappa_{2} \mathrm{~S}-\mathrm{\kappa}_{4} \mathrm{C}\right)(\mathrm{CO})_{10}\right\}\left(\mu_{3}-\mathrm{S}\right)_{2} \mathrm{Fe}(\mathrm{CO})_{3}\right](6)$ (Figure 11). Average bond distances are quite similar to those in 5 , with the marked difference being the average $\mathrm{Fe}-\mathrm{S}$ of $2.25 \pm 0.03 \AA$ in 6, which is nearly identical with that of FeMoco. The key difference, however, displayed in 6 is the absence of a sulfur site ( $\mathrm{S} 4$ in 5 ), therefore, designating $\mathrm{S} 3$ as a second face-bridging sulfide $\left(\mathrm{S}^{2-}\right)$ site (in addition to S2). The absence of the $\mathrm{S} 4$ site, however, does induce a break in the $C_{\mathrm{S}}$ chemical symmetry displayed in cluster 5, such that the Fe5-Fe3 distance has shortened to 2.616(1) A. While we found that synthesis of cluster 6 has, in fact, been previously reported from the reaction of $\mathrm{Fe}_{3}(\mathrm{CO})_{12}$ with $\mathrm{CS}_{2}$ at $80^{\circ} \mathrm{C}$ [71], the conspicuous absence of this structure from the CSD coupled with the fact that the original report has seemingly remained in obscurity from the bioinorganic synthetic modelling community has hindered its utilization as a clear candidate for nitrogenase structural modeling.

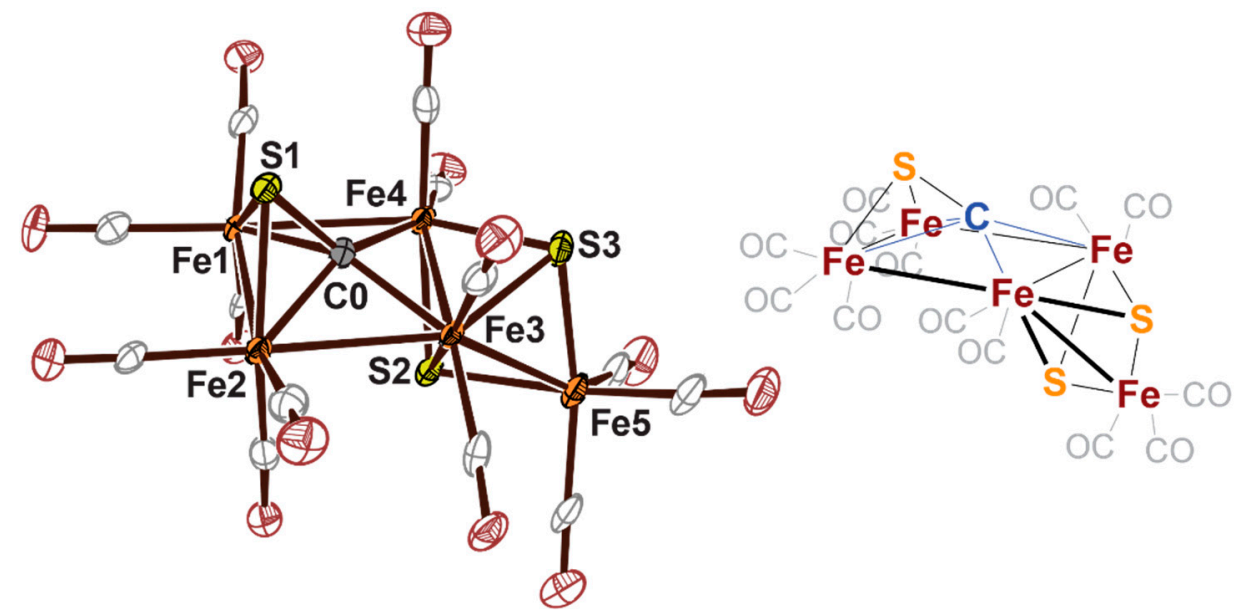

Figure 11. Thermal ellipsoid plots (50\% probability) of $\left[\left\{\mathrm{Fe}_{4}\left(\kappa_{2} \mathrm{~S}-\kappa_{4} \mathrm{C}\right)(\mathrm{CO})_{10}\right\}\left(\mu_{3}-\mathrm{S}\right)_{2} \mathrm{Fe}(\mathrm{CO})_{3}\right](6)$. Orange $=\mathrm{Fe}$, Gray $=\mathrm{C}$, Yellow $=\mathrm{S}$, Maroon $=$ O. Image adapted with permission from Joseph, C., Cobb, C. R., Rose, M. J. Single-Step Insertion of Sulfides and Thiolate into Iron Carbide-Carbonyl Clusters: Unlocking the Synthetic Door to FeMoco Analogues. Angew. Chemie Int. Ed. 2020, Accepted, not yet published. Copyright Wiley-VCH GmbH. Reproduced with permission.

In addition to the biologically relevant bond metrics observed in the two $\{\mathrm{CS}\}$-containing clusters, we found that the dangler Fe site in cluster $\mathbf{5}$ also approaches similarly relevant electronic properties (i.e., approaching a ferrous oxidation state). X-ray photoelectron spectroscopy (XPS) of 5 could be fit as 3 distinct components at both the Fe $2 p(3 / 2)$ region $(711.6,709.4$, and $707.5 \mathrm{eV}$ ) and the Fe $2 p(1 / 2)$ region $(724.6,722.2$, and $720.5 \mathrm{eV}$ ) with integrated peak area ratios of 1:2:2, respectively (Figure 12). On the basis of symmetry, the Fe5 site could be assigned to the higher binding energy peak (highest valence state Fe site). This assignment was additionally supplemented by density-functional theory (DFT) calculations, indicating Fe5 to be the Fe site with the least electron density on the basis of Mulliken population analysis and back-bonding contribution into the coordinated COs. The assignment of XPS peaks at $711.6 \mathrm{eV}$ and $724.6 \mathrm{eV}$ additionally falls within the expected range for a ferrous and CO-supported iron site [72,73]. The conclusions drawn from the XPS data are also consistent with the higher $\mathrm{CO}$ stretching frequencies observed in the IR spectrum in which all $v_{\mathrm{CO}}$ values range upward from $2002 \mathrm{~cm}^{-1}$. These are significantly blue-shifted relative to $3\left(v_{\mathrm{CO}} \geq 1973 \mathrm{~cm}^{-1}\right)$ and $4\left(v_{\mathrm{CO}} \geq 1991 \mathrm{~cm}^{-1}\right)$ and is additionally consistent with the presence of a ferrous site, which is not typically observed in CO-supported FeC clusters. 


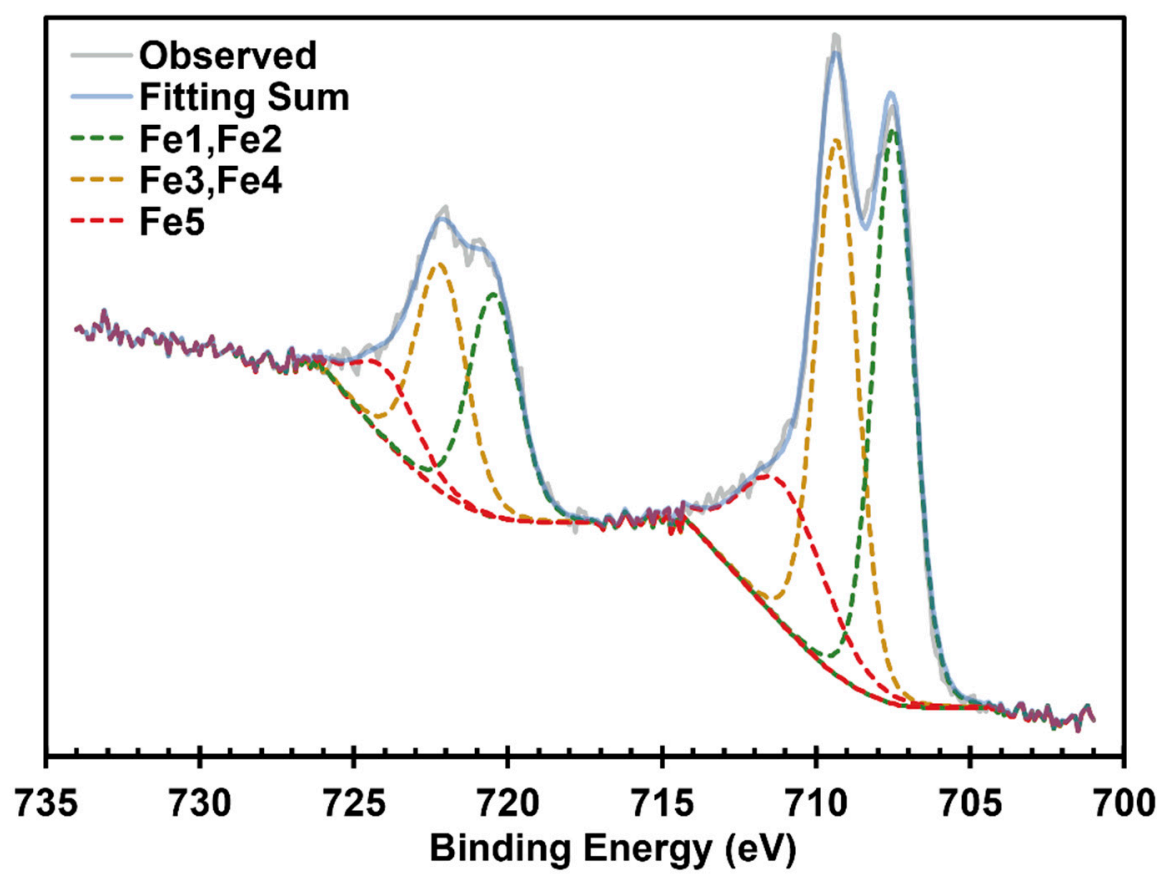

Figure 12. Observed high-resolution $X$-ray photoelectron spectrum (XPS) and component fitting of the iron $2 p$ region of cluster 5 . Image adapted with permission from Joseph, C., Cobb, C. R., Rose, M. J. Single-Step Insertion of Sulfides and Thiolate into Iron Carbide-Carbonyl Clusters: Unlocking the Synthetic Door to FeMoco Analogues. Angew. Chemie Int. Ed. 2020, Accepted, not yet published. Copyright Wiley-VCH GmbH. Reproduced with permission.

In many respects, the construction of clusters 5 and $\mathbf{6}$ elevates the family of carbonyl-supported, carbide-containing iron clusters into the realm of highly structurally relevant models for the nitrogenase active site. Comparison of bond metrics between the clusters with FeMoco (Table 1) conveys the approaching similarity in $\mathbf{5}$ and $\mathbf{6}$ toward that analogous FeMoco metrics. However, the presence of a true $C-S$ bond [1.714(5) $\AA$ ] does preclude the $C$ from being an authentic $\mathrm{C}^{4-}$ carbide. Nonetheless, this unusual bonding motif (only three entries in the CSD for transition-metal-bound $\{C-S\}$-none of which contain iron) is reminiscent of the proposed biogenesis mode of carbide insertion into the M-cluster as postulated by Wiig, $\mathrm{Hu}$, and Ribbe depicted in Figure $2[11,12]$. The presence of the $\{\mathrm{C}-\mathrm{S}\}^{4-}$ motif (i.e., tetra-deprotonated methylthiol) in $\mathbf{5}$ and $\mathbf{6}$, thus, serves as the first rudimentary structural model for intermediates in M-cluster biosynthesis. Such intermediates would likely be difficult to isolate for crystallographic characterization. On the other hand, comparative spectroscopic studies of synthetic cluster compounds have previously demonstrated utility in the determination of structural aspects of nitrogenase, such as the assignment of the central carbide (which itself utilized the $\mathrm{Fe}_{6}$ cluster precursor described above as a reference compound) [8,9]. The assortment of iron clusters that have been developed by our lab now present a range of reference compounds available for spectroscopic characterization and comparison against the various stages of nitrogenase biosynthesis: Clusters 1 and 2 provide examples of comparable alkylated and non-alkylated FeS clusters as appropriate for early-stage NifB reactions, while clusters 5 and $\mathbf{6}$ bearing the $\{C-S\}$ motif present model compounds for intermediates in late-stage NifB activity. 
Table 1. Selected bond distance averages of the FeCS clusters described in this work compared with the corresponding averages found in the nitrogenase cofactor (FeMoco).

\begin{tabular}{cccccc}
\hline & $\mathbf{3}$ & $\mathbf{4}$ & $\mathbf{5}$ & $\mathbf{6}$ & FeMoco \\
\hline Fe-Fe & $\mathbf{2 . 6 5} \pm 0.06$ & $\mathbf{2 . 6 4} \pm 0.05$ & $\mathbf{2 . 6 6} \pm 0.09$ & $\mathbf{2 . 7} \pm 0.1$ & $\mathbf{2 . 6 3} \pm 0.04$ \\
$\mathrm{Fe}-\mathrm{C}$ & $\mathbf{1 . 8 8} \pm 0.03$ & $\mathbf{1 . 8 8} \pm 0.04$ & $\mathbf{1 . 9 7} \pm 0.04$ & $\mathbf{1 . 9 6} \pm 0.02$ & $\mathbf{2 . 0 0} \pm 0.02$ \\
$\mathrm{Fe}-\mathrm{S}$ & $\mathbf{2 . 1 9} \pm 0.01$ & $\mathbf{2 . 1 7 5} \pm 0.005$ & $\mathbf{2 . 2 7} \pm 0.03$ & $\mathbf{2 . 2 5} \pm 0.03$ & $\mathbf{2 . 2 5} \pm 0.03$ \\
\hline
\end{tabular}

\section{Extension of Electrophilic Sulfur Ligation toward Fine-Tuning of Cluster Thiolates}

\subsection{Electronic Effects of Fe-Alkyl Bonding in Iron-Sulfur Cubane Clusters}

The alkylated clusters generated by the Suess group (vide supra) illustrate how binding of an alkyl fragment at a single iron site significantly alters the oxidation states of the irons within the cluster. Classically, a $\left[\mathrm{Fe}_{4} \mathrm{~S}_{4}\right]^{2+}$ cluster with relatively weak-field and uniform ligands features an overall $\mathrm{S}=0$ spin state with four $\mathrm{Fe}^{2.5+}$ sites in high-spin configurations featuring double exchange within two pairs of $\left[\mathrm{Fe}_{2} \mathrm{~S}_{2}\right]^{+}$units that antiferromagnetically couple with each other. This holds true for the chloride precursor of the $\left[\mathrm{Fe}_{4} \mathrm{~S}_{4}\right]^{2+}$-ethyl cluster and for many thiolate-ligated protein-bound $\left[\mathrm{Fe}_{4} \mathrm{~S}_{4}\right]^{2+}$ clusters. Suess et al. show that the introduction of a strong-field, electron rich alkyl ligand at the apical iron site polarizes the double-exchange interaction and introduces ferric character at the apical alkyl-bound iron. Correspondingly, it introduces ferrous character at its spin-aligned partner iron site with no overall change in charge [48].

This effect was replicated in the reported $\left[\mathrm{Fe}_{4} \mathrm{~S}_{4}\right]^{3+}$-methyl structure where the ferric character was found to be localized at the alkylated iron site. Furthermore, solution studies of this structure suggest rapid interconversion of the oxidation states at the three chelated iron sites, resulting in a shared oxidation state of essentially $2.67+$. Overall, alkylation has a profound and unique effect on oxidation states of the irons within both the $2+$ and the $3+\mathrm{Fe}_{4} \mathrm{~S}_{4}$ clusters [49]. These two synthetic structures represent the first direct bioinorganic insight into Fe-alkyl bonding and the electronic attributes of $\mathrm{Fe}_{4} \mathrm{~S}_{4}$-alkyl intermediates in nature. Perhaps most essential for the field, the range of chelating ligand scaffolds employed, and the demonstrated impact of remote steric effects on apical substrate binding in this class of clusters promise a drastic increase in the degree of synthetic control over iron-sulfur clusters [74]. This approach has already allowed for the isolation of increasingly elusive intermediates as well as the study of the reactivity of radical formation from alkyl intermediates $[48,49,75]$, and suggests one possible route toward controlling the environment of reactive intermediates and active sites in other iron-sulfur metalloclusters as well.

\subsection{New Routes toward Carbide-Containing Iron-Thiolato Clusters}

The structure and reactivity of these alkyl clusters present novel findings relevant to radical SAM, but not directly relevant to the NifB intermediate. However, the growing family of chelating ligands and the control they afford over the oxidation states and reactivities of these clusters suggest new directions in rational cluster design that may yield novel insights into nitrogenase biogenesis intermediates [48,49]. Potential for any ligand-directed, cluster-based nitrogenase modeling remains to be borne out, but the recent results from Suess et al. suggest the stabilization of more reactive metalloclusters may be accessible through the design of suitable chelating ligand systems.

Historically, controlled ligation of sulfides and thiolates onto iron carbonyl carbide clusters has proven difficult to control and would generally result in cluster decomposition. However, upon the discovery that the $\left[\mathrm{Fe}_{6}\right]$ dianion was amenable toward substitution by an electrophilic sulfur source, we elected to extend the utility of this synthetic strategy toward the incorporation of a thiolato ligand. As a proof of concept, $p$-toluenesulfenyl chloride was reacted with the $\left[\mathrm{Fe}_{6}\right]^{2-}$ cluster, yielding pink crystals of the first-ever reported thiolato-iron-carbide cluster (Figure 13) [67]. This controlled ligation of an iron-carbide cluster presents an as-yet-unrealized golden opportunity to finally engage this family of interstitial carbide clusters to be functionally "fine-tuned" with the introduction of an electronically 
diverse range of ligands. As such, a new branch has sprouted in our own research program, and a pursuit for elegantly designed, functionally active carbide-containing iron clusters, which have, for so long, evaded the synthetic modeling community, may now be forthcoming.

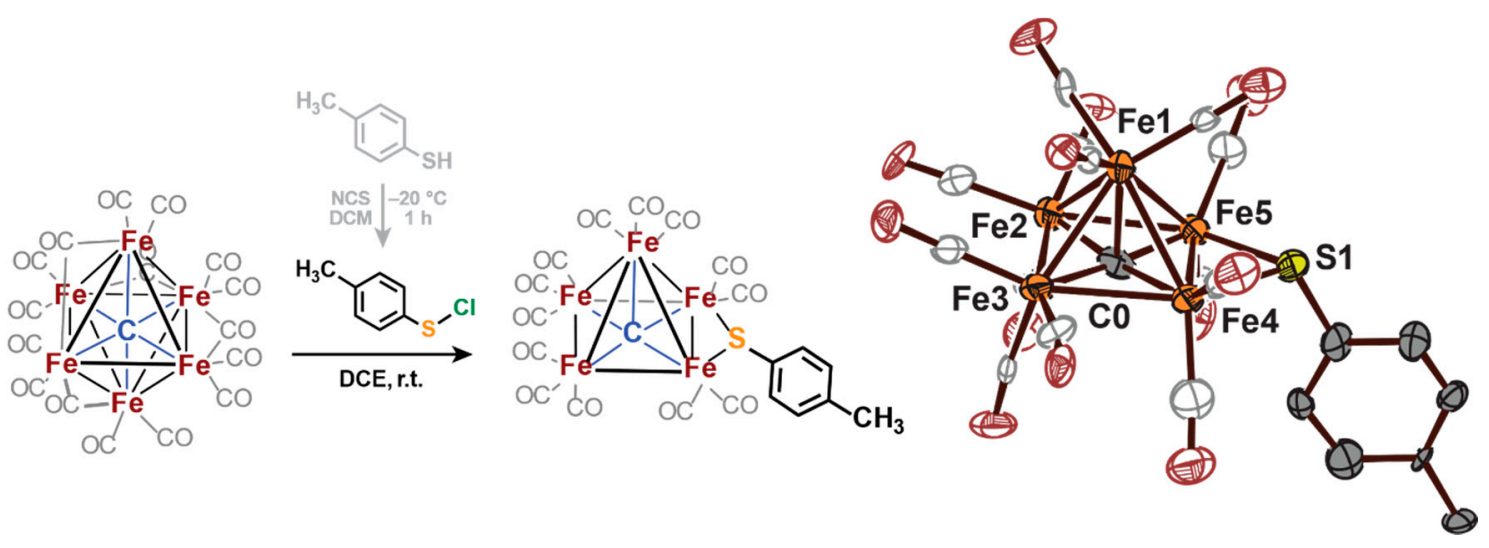

Figure 13. Reaction conditions (left) to obtain $\left(\mathrm{NEt}_{4}\right)\left[\mathrm{Fe}_{5}\left(\mu_{5}-\mathrm{C}\right)\left(\mathrm{SC}_{7} \mathrm{H}_{7}\right)(\mathrm{CO})_{13}\right]$ and thermal ellipsoid plots (50\% probability) of the thiolate-bearing cluster anion (right). Image adapted with permission from Joseph, C., Cobb, C. R., Rose, M. J. Single-Step Insertion of Sulfides and Thiolate into Iron Carbide-Carbonyl Clusters: Unlocking the Synthetic Door to FeMoco Analogues. Angew. Chemie Int. Ed. 2020, Accepted, not yet published. Copyright Wiley-VCH GmbH. Reproduced with permission.

\section{Closing Remarks}

The pursuit for model compounds of structural relevance to FeMoco continues to inspire many creative research avenues for synthetic chemists. Still, the "Holy Grail" for synthetic FeMoco modeling - a paramagnetic iron cluster with inorganic sulfides, an interstitial carbide, and heterometal Mo-remains unaccomplished. Success in this pursuit will allow for insight into the role of the carbide as a structural and electronic modulator in nitrogenase and understanding into how the electronic properties of NifB affect carbide incorporation. Thus far, synthetic models focusing on FeMoco have shown that the carbide likely facilitates structural flexibility of the cluster and even promotes substrate binding and reduction (vide supra). Other modelling avenues have given insight into how such a C-donor ligand may promote very strong antiferromagnetic coupling in the cluster and play a significant electronic role in the cofactor.

In our own venture to progress ever closer toward achieving this goal, we have utilized carbidocarbonyl iron clusters as a synthetic starting point for structural modeling of the nitrogenase cofactor. While $\left[\mathrm{Fe}_{6}\left(\mu_{6}-\mathrm{C}\right)(\mathrm{CO})_{16}\right]^{2-}$ had previously served a crucial role in the assignment of the interstitial carbide in FeMoco (and later FeVco), further utilization of carbonyl-clusters for nitrogenase modelling is sparse. For our own research, a two-fold strategy toward pursuing nitrogenase-relevant synthetic clusters was employed. First, inspiration was taken from the radical-initiated biosynthetic mechanism as proposed by Ribbe and $\mathrm{Hu}$ in which an initial SAM methylates the K-cluster. The methylated FeS cluster is subsequently dehydrogenated by an additional equivalent of SAM. The pursuit of this strategy for carbide insertion led us to explore TEMPO-mediated reactions upon alkylated $\mathrm{Fe}_{3} \mathrm{~S}$ clusters. Although carbide insertion ultimately proved unsuccessful, the methylated precursor clusters were successfully isolated and characterized. Along with the $\mathrm{Fe}_{3} \mathrm{~S}$ precursor $\left[\mathrm{Fe}_{3}\left(\mu_{3}-\mathrm{S}\right)(\mathrm{CO})_{9}\right]$, these clusters do provide a structurally interesting synthetic comparison for early-stage NifB reactions. In an alternative synthetic strategy, the carbide-containing $\mathrm{Fe}_{6}$ cluster served as a starting point for sulfurization reactions. The reaction with electropositive sulfur reagents proved successful in achieving an FeCS cluster, and we were additionally pleased to discover two $\{C-S\}^{4-}$-containing clusters, building upon our series of biogenesis-relevant models with appropriate compounds for late-stage NifB reactivity modeling. Future pursuits to close the gap between the early-stage and late-stage NifB models would see us aspire toward partially protonated/hydrogenated $\left\{\mathrm{SCH}_{2}\right\}$ and $\{\mathrm{SCH}\}$ structures [76]. 
Author Contributions: Writing-Original draft, C.J., J.P.S. and C.R.C. Visualization, C.J. Funding acquisition, M.J.R. Supervision, M.J.R. All authors have read and agreed to the published version of the manuscript.

Funding: The research related in this perspective was funded by the National Science Foundation (NSF CHE-1808311) and the Robert A. Welch Foundation (F-1822).

Conflicts of Interest: The authors declare no conflict of interest.

\section{References}

1. Hoffman, B.M.; Lukoyanov, D.; Yang, Z.-Y.; Dean, D.R.; Seefeldt, L.C. Mechanism of nitrogen fixation by nitrogenase: The next stage. Chem. Rev. 2014, 114, 4041. [CrossRef] [PubMed]

2. Eady, R.R. Structure-function relationships of alternative nitrogenases. Chem. Rev. 1996, 96, 3013. [CrossRef] [PubMed]

3. Georgiadis, M.M.; Komiya, H.; Chakrabarti, P.; Woo, D.; Kornuc, J.J.; Rees, D.C. Crystallographic structure of the nitrogenase iron protein from Azotobacter vinelandii. Science 1992, 257, 1653. [CrossRef] [PubMed]

4. Kim, J.; Rees, D.C. Structural models for the metal centers in the nitrogenase molybdenum-iron protein. Science 1992, 257, 1677. [CrossRef]

5. Einsle, O.; Tezcan, F.A.; Andrade, S.L.A.; Schmid, B.; Yoshida, M.; Howard, J.B.; Rees, D.C. Nitrogenase MoFe-protein at $1.16 \AA$ resolution: A central ligand in the FeMo-cofactor. Science 2002, 297, 1696. [CrossRef]

6. Smith, B.E. Nitrogenase reveals its inner secrets. Science 2002, 297, 1654. [CrossRef]

7. Spatzal, T.; Aksoyoglu, M.; Zhang, L.; Andrade, S.L.A.; Schleicher, E.; Weber, S.; Rees, D.C.; Einsle, O. Evidence for interstitial carbon in nitrogenase FeMo cofactor. Science 2011, 334, 940. [CrossRef]

8. Lancaster, K.M.; Roemelt, M.; Ettenhuber, P.; Hu, Y.; Ribbe, M.W.; Neese, F.; Bergmann, U.; DeBeer, S. X-ray emission spectroscopy evidences a central carbon in the nitrogenase iron-molybdenum cofactor. Science 2011, 334, 974. [CrossRef]

9. Delgado-Jaime, M.U.; Dible, B.R.; Chiang, K.P.; Brennessel, W.W.; Bergmann, U.; Holland, P.L.; DeBeer, S. Identification of a single light atom within a multinuclear metal cluster using valence-to-core $\mathrm{X}$-ray emission spectroscopy. Inorg. Chem. 2011, 50, 10709. [CrossRef]

10. Frey, P.A.; Hegeman, A.D.; Ruzicka, F.J. The radical SAM superfamily. Crit. Rev. Biochem. Mol. Biol. 2008, 43, 63. [CrossRef]

11. Wiig, J.A.; Hu, Y.; Lee, C.C.; Ribbe, M.W. Radical SAM-dependent carbon insertion into the nitrogenase M-cluster. Science 2012, 337, 1672. [CrossRef] [PubMed]

12. Wiig, J.A.; Hu, Y.; Ribbe, M.W. Refining the pathway of carbide insertion into the nitrogenase M-cluster. Nat. Commun. 2015, 6, 8034. [CrossRef] [PubMed]

13. Rettberg, L.A.; Wilcoxen, J.; Lee, C.C.; Stiebritz, M.T.; Tanifuji, K.; Britt, R.D.; Hu, Y. Probing the Coordination and Function of $\mathrm{Fe}_{4} \mathrm{~S}_{4}$ Modules in Nitrogenase Assembly Protein NifB. Nat. Commun. 2018, 9, 2824. [CrossRef] [PubMed]

14. Pierre, S.; Guillot, A.; Benjdia, A.; Sandström, C.; Langella, P.; Berteau, O. Thiostrepton Tryptophan Methyltransferase Expands the Chemistry of Radical SAM Enzymes. Nat. Chem. Biol. 2012, 8, 957. [CrossRef]

15. Marous, D.R.; Lloyd, E.P.; Buller, A.R.; Moshos, K.A.; Grove, T.L.; Blaszczyk, A.J.; Booker, S.J.; Townsend, C.A. Consecutive Radical S -Adenosylmethionine Methylations Form the Ethyl Side Chain in Thienamycin Biosynthesis. Proc. Natl. Acad. Sci. USA 2015, 112, 10354. [CrossRef]

16. Sickerman, N.S.; Ribbe, M.W.; Hu, Y. Nitrogenase cofactor assembly: An elemental inventory. Acc. Chem. Res. 2017, 50, 2834. [CrossRef]

17. Jasniewski, A.J.; Wilcoxen, J.; Tanifuji, K.; Hedman, B.; Hodgson, K.O.; Britt, R.D.; Hu, Y.; Ribbe, M.W. Spectroscopic characterization of an eight-iron nitrogenase cofactor precursor that lacks the "9th sulfur". Angew. Chem. Int. Ed. 2019, 58, 14703. [CrossRef]

18. Tanifuji, K.; Lee, C.C.; Sickerman, N.S.S.; Tatsumi, K.; Ohki, Y.; Hu, Y.; Ribbe, M.W. Tracing the 'ninth sulfur' of the nitrogenase cofactor via a semi-synthetic approach. Nat. Chem. 2018, 10, 568. [CrossRef]

19. Van Stappen, C.; Thorhallsson, A.T.; Decamps, L.; Bjornsson, R.; DeBeer, S. Resolving the structure of the $\mathrm{E}_{1}$ state of Mo nitrogenase through Mo and Fe K-edge EXAFS and QM/MM calculations. Chem. Sci. 2019, 10, 9807. [CrossRef] 
20. Van Stappen, C.; Davydov, R.; Yang, Z.-Y.; Fan, R.; Guo, Y.; Bill, E.; Seefeldt, L.C.; Hoffman, B.M.; DeBeer, S. Spectroscopic description of the $\mathrm{E}_{1}$ state of Mo nitrogenase based on Mo and Fe X-ray absorption and Mössbauer studies. Inorg. Chem. 2019, 58, 12365. [CrossRef]

21. Yandulov, D.V.; Schrock, R.R. Catalytic reduction of dinitrogen to ammonia at a single molybdenum center. Science 2003, 301, 76. [CrossRef] [PubMed]

22. Anderson, J.S.; Rittle, J.; Peters, J.C. Catalytic conversion of nitrogen to ammonia by an iron model complex. Nature 2013, 501, 84. [CrossRef] [PubMed]

23. Spatzal, T.; Perez, K.A.; Einsle, O.; Howard, J.B.; Rees, D.C. Ligand binding to the FeMo-cofactor: Structures of CO-bound and reactivated nitrogenase. Science 2014, 345, 1620. [CrossRef] [PubMed]

24. Spatzal, T.; Perez, K.A.; Howard, J.B.; Rees, D.C. Catalysis-dependent selenium incorporation and migration in the nitrogenase active site iron-molybdenum cofactor. eLife 2015, 4, 1. [CrossRef] [PubMed]

25. Sippel, D.; Rohde, M.; Netzer, J.; Trncik, C.; Gies, J.; Grunau, K.; Djurdjevic, I.; Decamps, L.; Andrade, S.L.A.; Einsle, O. A bound reaction intermediate sheds light on the mechanism of nitrogenase. Science 2018, 359, 1484. [CrossRef]

26. Siegbahn, P.E.M. A major structural change of the homocitrate ligand of probable importance for the nitrogenase mechanism. Inorg. Chem. 2018, 57, 1090. [CrossRef]

27. Kang, W.; Lee, C.C.; Jasniewski, A.J.; Ribbe, M.W.; Hu, Y. Structural evidence for a dynamic metallocofactor during $\mathrm{N}_{2}$ reduction by Mo-nitrogenase. Science 2020, 368, 1381. [CrossRef]

28. Arashiba, K.; Miyake, Y.; Nishibayashi, Y.A. Molybdenum complex bearing PNP-type pincer ligands leads to the catalytic reduction of dinitrogen into ammonia. Nat. Chem. 2011, 3, 120. [CrossRef]

29. Nishibayashi, Y. Recent progress in transition-metal-catalyzed reduction of molecular dinitrogen under ambient reaction conditions. Inorg. Chem. 2015, 54, 9234. [CrossRef]

30. Kuriyama, S.; Arashiba, K.; Nakajima, K.; Matsuo, Y.; Tanaka, H.; Ishii, K.; Yoshizawa, K.; Nishibayashi, Y. Catalytic transformation of dinitrogen into ammonia and hydrazine by iron-dinitrogen complexes bearing pincer ligand. Nat. Commun. 2016, 7, 12181. [CrossRef]

31. Lee, Y.; Mankad, N.P.; Peters, J.C. Triggering $\mathrm{N}_{2}$ uptake via redox-induced expulsion of coordinated $\mathrm{NH}_{3}$ and $\mathrm{N}_{2}$ silylation at trigonal bipyramidal iron. Nat. Chem. 2010, 2, 558. [CrossRef] [PubMed]

32. Creutz, S.E.; Peters, J.C. Catalytic reduction of $\mathrm{N}_{2}$ to $\mathrm{NH}_{3}$ by an $\mathrm{Fe}-\mathrm{N}_{2}$ complex featuring a C-atom anchor. J. Am. Chem. Soc. 2014, 136, 1105. [CrossRef] [PubMed]

33. Rittle, J.; Peters, J.C. An Fe- $\mathrm{N}_{2}$ complex that generates hydrazine and ammonia via $\mathrm{Fe}=\mathrm{NNH}_{2}$ : Demonstrating a hybrid distal-to-alternating pathway for $\mathrm{N}_{2}$ reduction. J. Am. Chem. Soc. 2016, 138, 4243. [CrossRef] [PubMed]

34. Creutz, S.E.; Peters, J.C. Diiron bridged-thiolate complexes that bind $\mathrm{N}_{2}$ at the $\mathrm{Fe}^{\mathrm{II}} \mathrm{Fe}^{\mathrm{II}}, \mathrm{Fe}^{\mathrm{II}} \mathrm{Fe}^{\mathrm{I}}$, and $\mathrm{Fe}^{\mathrm{I}} \mathrm{Fe}^{\mathrm{I}}$ redox states. J. Am. Chem. Soc. 2015, 137, 7310. [CrossRef]

35. Čorić, I.; Mercado, B.Q.; Bill, E.; Vinyard, D.J.; Holland, P.L. Binding of dinitrogen to an iron-sulfur-carbon site. Nature 2015, 526, 96. [CrossRef]

36. Groom, C.R.; Bruno, I.J.; Lightfoot, M.P.; Ward, S.C. The Cambridge Structural Database. Acta Crystallogr. 2016, B72, 171. [CrossRef]

37. Kovacs, J.A.; Holm, R.H. Assembly of vanadium-iron-sulfur cubane clusters from mononuclear and linear trinuclear reactants. J. Am. Chem. Soc. 1986, 108, 340. [CrossRef]

38. Fomitchev, D.V.; McLauchlan, C.C.; Holm, R.H. Heterometal cubane-type $\mathrm{MFe}_{3} \mathrm{~S}_{4}$ clusters $(\mathrm{M}=\mathrm{Mo}, \mathrm{V})$ trigonally symmetrized with Hydrotris(Pyrazolyl)Borate(1-) and Tris(Pyrazolyl)Methanesulfonate(1-) capping ligands. Inorg. Chem. 2002, 41, 958. [CrossRef]

39. Rees, J.A.; Bjornsson, R.; Kowalska, J.K.; Lima, F.A.; Schlesier, J.; Sippel, D.; Weyhermüller, T.; Einsle, O.; Kovacs, J.A.; DeBeer, S. Comparative electronic structures of nitrogenase FeMoco and FeVco. Dalt. Trans. 2017, 46, 2445. [CrossRef]

40. Reed, C.J.; Agapie, T. Tetranuclear Fe clusters with a varied interstitial ligand: Effects on the structure, redox properties, and nitric oxide activation. Inorg. Chem. 2017, 56, 13360. [CrossRef]

41. Arnett, C.H.; Kaiser, J.T.; Agapie, T. Remote ligand modifications tune electronic distribution and reactivity in site-differentiated, high-spin iron clusters: Flipping scaling relationships. Inorg. Chem. 2019, 58, 15971. [CrossRef] [PubMed]

42. Taniyama, N.; Ohki, Y.; Tatsumi, K. Synthesis of V/Fe/S clusters using Vanadium(III) thiolate complexes bearing a phenoxide-based tridentate ligand. Inorg. Chem. 2014, 53, 5438. [CrossRef] [PubMed] 
43. Ohta, S.; Ohki, Y.; Hashimoto, T.; Cramer, R.E.; Tatsumi, K. A nitrogenase cluster model $\left[\mathrm{Fe}_{8} \mathrm{~S}_{6} \mathrm{O}\right]$ with an oxygen unsymmetrically bridging two proto- $\mathrm{Fe}_{4} \mathrm{~S}_{3}$ cubes: Relevancy to the substrate binding mode of the FeMo cofactor. Inorg. Chem. 2012, 51, 11217. [CrossRef] [PubMed]

44. Liu, L.; Rauchfuss, T.B.; Woods, T.J. Iron carbide-sulfide carbonyl clusters. Inorg. Chem. 2019, $58,8271$. [CrossRef] [PubMed]

45. Liu, L.; Woods, T.J.; Rauchfuss, T.B. Reactions of $\left[\mathrm{Fe}_{6} \mathrm{C}(\mathrm{CO})_{14}(\mathrm{~S})\right]^{2-}$ : Cluster growth, redox, sulfiding. Eur. J. Inorg. Chem. 2020, 36, 3460.

46. Churchill, M.R.; Wormald, J.; Knight, J.; Mays, M.J. Synthesis and crystallographic characterization of bis(tetramethylammonium) carbidohexadecacarbonylhexaferrate, a hexanuclear carbidocarbonyl derivative of iron. J. Am. Chem. Soc. 1971, 93, 3073. [CrossRef]

47. Churchill, M.R.; Wormald, J. Crystal and molecular structure of tetramethylammonium carbidohexadecacarbonylhexaferrate (2-), $\left[\mathrm{Me}_{4} \mathrm{~N}_{2}\left[\mathrm{Fe}_{6}(\mathrm{CO})_{16} \mathrm{C}\right]\right.$, a hexanuclear iron cluster complex with an encapsulated six-co-ordinate carbon atom. J. Chem. Soc. Dalt. Trans. 1974, 2410-2415. [CrossRef]

48. Ye, M.; Thompson, N.B.; Brown, A.C.; Suess, D.L.M. A synthetic model of enzymatic $\left[\mathrm{Fe}_{4} \mathrm{~S}_{4}\right]-\mathrm{alkyl}$ intermediates. J. Am. Chem. Soc. 2019, 141, 13330. [CrossRef]

49. McSkimming, A.; Sridharan, A.; Thompson, N.B.; Müller, P.; Suess, D.L.M. An $\left[\mathrm{Fe}_{4} \mathrm{~S}_{4}\right]^{3+}$-alkyl cluster stabilized by an expanded scorpionate ligand. J. Am. Chem. Soc. 2020, 142, 14314. [CrossRef]

50. Ni, C.; Power, P.P. Methyl-bridged transition metal complexes ( $\mathrm{M}=\mathrm{Cr}-\mathrm{Fe})$ supported by bulky terphenyl ligands. Organometallics 2009, 28, 6541. [CrossRef]

51. Sun, C.L.; Krause, H.; Fürstner, A. A practical procedure for iron-catalyzed cross-coupling reactions of sterically hindered aryl-grignard reagents with primary alkyl halides. Adv. Synth. Catal. 2014, 356, 1281. [CrossRef]

52. Klose, A.; Solari, E.; Floriani, C.; Chiesi-Villa, A.; Rizzoli, C.; Re, N. Magnetic Properties Diagnostic for the Existence of Iron(II)-Iron(II) Bonds in Dinuclear Complexes Which Derive from Stepwise Insertion Reactions on Unsupported Iron-Aryl Bonds. J. Am. Chem. Soc. 1994, 116, 9123. [CrossRef]

53. Yogendra, S.; Weyhermüller, T.; Hahn, A.W.; DeBeer, S. From Ylides to Doubly Yldiide-Bridged Iron(II) High Spin Dimers via Self-Protolysis. Inorg. Chem. 2019, 58, 9358. [CrossRef] [PubMed]

54. Nagelski, A.L.; Fataftah, M.S.; Bollmeyer, M.M.; McWilliams, S.F.; MacMillan, S.N.; Mercado, B.Q.; Lancaster, K.M.; Holland, P.L. The influences of carbon donor ligands on biomimetic multi-iron complexes for $\mathrm{N}_{2}$ reduction. Chem. Sci. 2020, in press. [CrossRef]

55. Booker, S.J.; Grove, T.L. Mechanistic and functional versatility of radical SAM enzymes. F1000 Biol. Rep. 2010, 2, 52. [CrossRef]

56. Braye, E.H.; Dahl, L.F.; Hubel, W.; Wampler, D.L. The preparation, properties and structure of the iron carbonyl carbide $\mathrm{Fe}_{5}(\mathrm{CO})_{15}$ C. J. Am. Chem. Soc. 1962, 84, 4633. [CrossRef]

57. Kuppuswamy, S.; Wofford, J.D.; Joseph, C.; Xie, Z.-L.; Ali, A.K.; Lynch, V.M.; Lindahl, P.A.; Rose, M.J. Structures, interconversions, and spectroscopy of iron carbonyl clusters with an interstitial carbide: Localized metal center reduction by overall cluster oxidation. Inorg. Chem. 2017, 56, 5998. [CrossRef]

58. Joseph, C.; Kuppuswamy, S.; Lynch, V.M.; Rose, M.J. Fe 5 Mo cluster with iron-carbide and molybdenum-carbide bonding motifs: Structure and selective alkyne reductions. Inorg. Chem. 2018, 57, 20. [CrossRef]

59. Rees, J.A.; Bjornsson, R.; Schlesier, J.; Sippel, D.; Einsle, O.; DeBeer, S. The Fe-V cofactor of vanadium nitrogenase contains an interstitial carbon atom. Angew. Chem. Int. Ed. 2015, 54, 13249. [CrossRef]

60. Cherng, J.-J.; Tsai, Y.-C.; Ueng, C.-H.; Lee, G.-H.; Peng, S.-M.; Shieh, M. New synthesis of $\left[\mathrm{SFe}_{3}(\mathrm{CO})_{9}\right]^{2-}$ and its reactivity toward electrophiles. Organometallics 2002, 17, 255. [CrossRef]

61. Kagalwala, H.N.; Lalaoui, N.; Li, Q.L.; Liu, L.; Woods, T.; Rauchfuss, T.B. Redox and "antioxidant" properties of $\mathrm{Fe}_{2}(\mu-\mathrm{SH})_{2}(\mathrm{CO})_{4}\left(\mathrm{PPh}_{3}\right)_{3}$. Inorg. Chem. 2019, 58, 2761. [CrossRef] [PubMed]

62. Wiig, J.A.; Hu, Y.; Ribbe, M.W. NifEN-B complex of Azotobacter vinelandii is fully functional in nitrogenase FeMo cofactor assembly. Proc. Natl. Acad. Sci. USA 2011, 108, 8623. [CrossRef] [PubMed]

63. Mokhtarzadeh, C.C.; Margulieux, G.W.; Carpenter, A.E.; Weidemann, N.; Moore, C.E.; Rheingold, A.L.; Figueroa, J.S. Synthesis and protonation of an encumbered iron tetraisocyanide dianion. Inorg. Chem. 2015, 54, 5579. [CrossRef] [PubMed] 
64. Caballero, C.; Nuber, B.; Ziegler, M.L. Darstellung und Charakterisierung von trigonal bipyramidalen methylidin-Clustern des Typs $\mathrm{EFe}_{3}(\mathrm{CO})_{9} \mathrm{CH}(\mathrm{E}=\mathrm{As}, \mathrm{Sb}, \mathrm{Bi})$ durch Umsetzung des Carbidoclusters $\mathrm{Fe}_{5} \mathrm{C}(\mathrm{CO})_{15}$ mit metallischem Arsen und Wismut Bzw. SbCl 5 . J. Organomet. Chem. 1990, 386, 209. [CrossRef]

65. Capps, K.B.; Wixmerten, B.; Bauer, A.; Hoff, C.D. Thermochemistry of sulfur atom transfer. Enthalpies of reaction of phosphines with sulfur, selenium, and tellurium, and of desulfurization of triphenylarsenic sulfide, triphenylantimony sulfide, and benzyl trisulfide. Inorg. Chem. 1998, 37, 2861. [CrossRef]

66. Bogdan, P.L.; Sabat, M.; Sunshine, S.A.; Woodcock, C.; Shriver, D.F. Anionic iron carbido carbonyl clusters with sulfur dioxide ligands. Inorg. Chem. 1988, 27, 1904. [CrossRef]

67. Joseph, C.; Cobb, C.R.; Rose, M.J. Single-Step Insertion of Sulfides and Thiolate into Iron Carbide-Carbonyl Clusters: Unlocking the Synthetic Door to FeMoco Analogues. Angew. Chemie Int. Ed. 2020, in press. [CrossRef]

68. Zhang, L.-M.; Morrison, C.N.; Kaiser, J.T.; Rees, D.C. Nitrogenase MoFe protein from Clostridium pasteurianum at 1.08 A resolution: Comparison with the Azotobacter vinelandii MoFe protein. Acta Crystallogr. Sect. D Biol. Crystallogr. 2015, 71, 274. [CrossRef]

69. Wei, C.H.; Dahl, L.F. Crystal structure of a 1:1 mixture of two iron carbonyl sulfur complexes, $\mathrm{S}_{2} \mathrm{Fe}_{3}(\mathrm{CO})_{9}$ and $\mathrm{S}_{2} \mathrm{Fe}_{2}(\mathrm{CO})_{6}$. Inorg. Chem. 1965, 4, 493. [CrossRef]

70. Bard, A.J.; Cowley, A.H.; Leland, J.K.; Thomas, G.J.N.; Norman, N.C.; Jutzi, P.; Morley, C.P.; Schlüter, E. Synthesis, structures, and reactivities of some pentamethylcyclopentadienyl-sulphur compounds. J. Chem. Soc. Dalt. Trans. 1985, 1303-1307. [CrossRef]

71. Broadhurst, P.V.; Johnson, B.F.G.; Lewis, J.; Raithby, P.R. Reaction of carbon disulfide with metal cluster carbonyls of the iron triad: Synthesis and X-ray structure of $\left[\mathrm{Fe}_{5}(\mathrm{CO}){ }_{13} \mathrm{~S}_{2}(\mathrm{CS})\right]$ containing a six-electron-donor thiocarbonyl group. J. Am. Chem. Soc. 1981, 103, 3198. [CrossRef]

72. Grosvenor, A.P.; Kobe, B.A.; Biesinger, M.C.; McIntyre, N.S. Investigation of multiplet splitting of Fe 2p XPS spectra and bonding in iron compounds. Surf. Interface Anal. 2004, 36, 1564. [CrossRef]

73. Barber, M.; Connor, J.A.; Guest, M.F.; Hall, M.B.; Hillier, I.H.; Meredith, W.N.E. High energy photoelectron spectroscopy of transition metal complexes. Part 1.-Bonding in substituted and unsubstituted first row carbonyls. Faraday Discuss. Chem. Soc. 1972, 54, 219. [CrossRef]

74. Brown, A.C.; Suess, D.L.M. Reversible formation of alkyl radicals at $\left[\mathrm{Fe}_{4} \mathrm{~S}_{4}\right]$ clusters and its implications for selectivity in radical SAM enzymes. J. Am. Chem. Soc. 2020, 142, 14240. [CrossRef] [PubMed]

75. Brown, A.C.; Suess, D.L.M. Controlling substrate binding to $\mathrm{Fe}_{4} \mathrm{~S}_{4}$ clusters through remote steric effects. Inorg. Chem. 2019, 58, 5273. [CrossRef] [PubMed]

76. Wawzonek, S.; Wearring, D. Polarographic studies in acetonitrile and dimethylformamide. IV. stability of anion-free radicals ${ }^{1,2}$. J. Am. Chem. Soc. 1959, 81, 2067. [CrossRef]

Publisher's Note: MDPI stays neutral with regard to jurisdictional claims in published maps and institutional affiliations.

(C) 2020 by the authors. Licensee MDPI, Basel, Switzerland. This article is an open access article distributed under the terms and conditions of the Creative Commons Attribution (CC BY) license (http://creativecommons.org/licenses/by/4.0/). 